\title{
MAÍRA DE ASSIS LIMA
}

Função da progesterona e da protease ADAMTS-1 na migração de células derivadas de câncer de ovário

Tese apresentada ao programa de Pós-graduação em Biologia de Sistemas, do Instituto de Ciências Biomédicas da Universidade de São Paulo, para a obtenção do título de Doutor em Ciências.

Área de concentração: Biologia Celular e Tecidual

Orientadora: Prof. ${ }^{a}$ Dr. ${ }^{\text {a }}$ Vanessa Morais Freitas

Versão Original 


\section{RESUMO}

\section{LIMA, M. A. Função da progesterona e da protease ADAMTS-1 na migração}

de células derivadas de câncer de ovário. 2019. 179 páginas. Tese de Doutorado em Biologia de Sistemas - Instituto de Ciências Biomédicas, Universidade de São Paulo, São Paulo, 2019.

A progressão do câncer depende não somente das habilidades adquiridas pelas células cancerigênas, mas também da interação entre as células e seu microambiente. Os componentes da matriz extracelular (MEC) estão envolvidos em vários aspectos da biologia tumoral, fornecendo não somente suporte sólido para as células, bem como citocinas e fatores de crescimento. As ADAMTSs (a disintegrin and metalloproteinase with thrombospondin motifs) são proteases secretadas dependentes de $\mathrm{Zn}^{2+} / \mathrm{Ca}^{2+}$ que estão envolvidas em diversos processos fisiológicos e patológicos. Já demonstramos que além de ter influência sobre os níveis gênicos e proteicos das ADAMTSs, a progesterona mostrou reduzir a capacidade migratória e invasiva das células de ovário $\mathrm{NIH}$ OVCAR-3 e ES-2 quando comparada às células sem tratamento. Nosso objetivo neste trabalho foi investigar por qual mecanismo a progesterona leva a diminuição da invasão e migração das células $\mathrm{CHO}$, NIH-OVCAR-3 e ES-2 e se a protease estudada está envolvida neste processo. Para isso, células derivadas de ovário tiveram os níveis de ADAMTS-1 modulados, tanto com o aumento ou diminuição, e foram comparadas com células parentais. Além disso, células com o gene de ADAMTS-1 modulado e células parentais foram tratadas com progesterona e comparadas com células não tratadas. A partir desses grupos, observou-se que o tratamento com $500 \mathrm{nM}$ ou $1 \mu \mathrm{M}$ de progesterona diminuiu a migração e invasão das células, em 24 horas ou menos, sem afetar a viabilidade, sendo que o uso do antagonista do receptor de progesterona, RU486, recuperou a capacidade migratória e invasiva das células. Tanto o tratamento com o meio enriquecido com ADAMTS-1 ou progesterona levaram a diminuição na migração e invasão celular quando comparadas aos controles. Por outro lado, a redução de ADAMTS-1 parece não prevenir a diminuição da migração celular quando estas são tratadas com progesterona. Por Immunoblot observou-se que 0 tratamento com $1 \mu \mathrm{M}$ de progesterona diminuiu a forma fosforilada de Src e FAK, 
moléculas que participam da cascata de sinalização envolvidas na ativação da migração e invasão celular. Utilizando o kit G-LISA®, medimos a forma GTP, ativa, de pequenas proteínas $\mathrm{G}$, a partir de lisados de células. O sinal de Cdc42GTP aumentou na presença de células com níveis reduzidos de ADAMTS-1 e tendeu a diminuir nas células tratadas com o meio enriquecido com ADAMTS-1. Esses dados foram confirmados através da análise do biosensor de Cdc42 transfectado em células ES-2 e analisado por FRET, que demostraram que esta GTPase está mais ativa e presente na borda de migração das células com diminuição de ADAMTS-1 em relação as células selvagens. Concluímos, portanto, que ADAMTS-1 e a progesterona atuam na inibição da proliferação, polarização, migração e crescimento sem adesão das células de câncer de ovário. Este efeito mostrou ser de forma independente por parte do hormônio e da protease estudados, mas não descarta que possa haver um trabalho em conjunto entre essas moleculas na redução de efeitos pro-tumorigênicos.

Palavras-chave: Câncer de ovário. Matriz extracelular. ADAMTS-1. Progesterona. Migração. Invasão. 


\section{ABSTRACT}

LIMA, M. A. Progesterone and ADAMTS-1 effects on ovarian cancer cells migration. 2019. 179 pages. PhD thesis in Systems Biology - Biomedical Science Institute, University of Sao Paulo, Sao Paulo, 2019.

The progression of cancer depends not only on the abilities acquired by neoplastic cells, but also on the interaction between cells and their microenvironment. Extracellular matrix (ECM) components are involved in various aspects of tumor biology, providing not only solid support for cells, but also cytokines and growth factors. ADAMTSs (disintegrin and metalloproteinase with thrombospondin motifs) are secreted proteases dependent on $\mathrm{Zn}^{2+} / \mathrm{Ca}^{2+}$, are involved in several processes and are part of the ECM. In a previous project, we demonstrated that progesterone influences on the gene and protein levels of ADAMTSs in ovarian cancer and it has been shown to reduce the migratory and invasive capacity of NIH-OVCAR-3 and ES-2 cells when compared to control cells. Our goal was to investigate by which mechanism progesterone leads to decreased invasion and migration of $\mathrm{CHO}$, NIH-OVCAR-3 and ES-2 and whether the protease studied is involved in this process. For this, ovary-derived cells had ADAMTS-1 levels modulated, either with increase or decrease, and were compared with parental cells. In addition, cells with the modulated ADAMTS-1 gene and parental cells underwent progesterone treatment and were compared to untreated cells. From these groups it was observed that treatment with $500 \mathrm{nM}$ or $1 \mu \mathrm{M}$ progesterone decreased cell migration and invasion, within 24 hours or less, without affecting viability, and the use of the progesterone receptor antagonist, RU486, recovered the migratory and invasive capacity. Both treatments, with the medium enriched with ADAMTS-1 or progesterone, led to a decrease in cell migration and invasion when compared to controls. On the other hand, the decresed levels of ADAMTS-1 does not seem to prevent the decrease of cellular migration when the cells are treated with progesterone. By Immunoblot, it was observed that treatment with $1 \mu \mathrm{M}$ progesterone decrease the phosphorylated form of Src and FAK, molecules that participate in the signaling cascade involved in the activation of cell migration and invasion. Using the GLISA $\AA$ kit evaluating the activity of Rho GTPases, we measured the active GTP form of small $G$ proteins from cell lysates. The Cdc42-GTP signal increased in 
the decresed levels of ADAMTS- 1 and tended to decrease in cells treated with ADAMTS-1-enriched medium. These data were confirmed by analysis of the transfected Cdc42 biosensor in ES-2 cells, which demonstrated that this GTPase is more active and present in the migration edge of the cells with decresed levels of ADAMTS-1 compared to the wild type cells. Therefore, we conclude that ADAMTS-1 and progesterone inhibit proliferation, polarization, migration and growth without adhesion of ovarian cancer cells. This effect has been shown to be independently to the hormone and protease studied, but does not rule out that there may be a joint work between these molecules in reducing pro-tumorigenic effects.

Keywords - Ovarian cancer. Extracellular matrix. ADAMTS-1. Progesterone. Migration. Invasion. 


\section{INTRODUÇÃO}

O câncer de ovário é o tumor ginecológico mais difícil de ser diagnosticado e o de menor chance de cura, pois devido à localização desses órgãos mais de $70 \%$ das mulheres apresentam a doença na forma avançada quando diagnosticadas (Ween et al., 2011). O risco para a doença, bem como sua gravidade, está envolvido com alterações em hormônios sexuais, que são capazes de modular a proliferação, apoptose, migração, metástase e angiogênese de células do câncer (Ramachandran, 2011). Já foi observado que mulheres pós-menopáusicas tem maior incidência desta doença, pois alternâncias hormonais associadas a este período, tais como uma diminuição nos níveis de estrogênio e de progesterona, e um consequente aumento do nível sistêmico dos hormônios gonadotróficos poderia ter um papel na manifestação deste tipo de câncer (Sapoznik et al., 2009). Além disso, a deficiência de progesterona, devido à menopausa, à infertilidade ou alterações no gene do receptor de progesterona (PR) estão associados com um risco aumentado de câncer de ovário (Edmondson and Monaghan, 2001; Syed et al., 2001).

A progesterona possui receptores na membrana de suas células alvo que quando ativados promovem respostas celulares que acarretam em dinâmicas na própria célula, interação com outras células e com o ambiente que as circunda. $O$ ambiente que circunda as células constitui a matriz extracelular (MEC), uma estrutura tridimensional altamente organizada que além de manter a integridade do tecido, também regula a migração, diferenciação e proliferação celular e fornece um reservatório de citocinas e fatores de crescimento. Esse microambiente é formado pelos componentes do estroma tumoral, fibroblastos, células endoteliais, células do sistema imunológico, proteínas e proteoglicanos da MEC, fatores de crescimento e proteases que remodelam esses componentes. Dentre as proteases conhecidas estão as ADAMTS (a disintegrin and metalloproteinase with thrombospondin), enzimas MMP-relacionadas dependentes de $\mathrm{Zn}^{2+} / \mathrm{Ca}^{2+}$ (Porter et al., 2005), secretadas e que formam um grupo composto por 19 membros que partilham de uma estrutura modular complexa, que compreende um domínio de metaloprotease, um domínio desintegrina e um domínio auxiliar contendo trombospondina do tipo 1, que é a marca desta família (Apte, 2004). Suas funções essenciais são sublinhadas pelo 
reconhecimento de que vários membros da família codificam genes responsáveis por doenças genéticas herdadas quando mutados, enquanto outros estão associados a patologias como câncer, artrite e doenças cardiovasculares (Mead and Apte, 2018) .

Fisiologicamente ADAMTS- 1 foi inicialmente descrita como um mediador da inflamação (Kuno et al., 1997), entretanto já foi demostrado que esta protease é necessária para o crescimento normal, além de auxiliar na estrutura e no funcionamento dos rins, da glândula adrenal e do aparelho reprodutor feminino (Shindo et al., 2000), participando da foliculogênese ovariana, na formação de vasos sanguíneos e linfáticos (Brown et al., 2006) e do processo de ovulação (Brown et al., 2010). Em relação a sua função nos tumores, ADAMTS-1 possui efeito anti-angiogênico (Vázquez, Hastings, et al., 1999), no entanto, alguns trabalhos mostram que ADAMTS-1 tem sua expressão aumentada em tumores de alto grau de malignidade (Masui et al., 2001), inclusive no câncer de ovário (Lima, Maíra Assis et al., 2016), talvez devido a sua capacidade de degradar o agrecan e o versican, os quais são componentes da matriz extracelular que funcionam como barreira a passagem das células. Dados do nosso laboratório mostram que, em tumores mais agressivos de mama, existe uma diminuição nos níveis de ADAMTS-1 quando comparados ao tecido normal (Freitas et al., 2013).

Em 2006 foi demonstrado que a ADAMTS-1 sofre auto-clivagem proteolítica, e que a protease de ADAMTS-1 com o domínio metaloproteinase ativo e os seus fragmentos exibem atividade pro- $e$ anti-tumoral, respectivamente. Observou-se também que a atividade de metaloproteinase de ADAMTS-1 é necessária para o seu potencial pro-tumoral, favorecendo a metástase. Além disso, foi demonstrado que a atividade anti-tumoral dos fragmentos de ADAMTS-1 dependem do motivo TSP-1 central, que é mascarado na molécula de comprimento total, indicando que o efeito de ADAMTS-1 sobre a metástase do tumor depende se a molécula está clivada ou intacta (Liu et al., 2006).

Estudos do nosso grupo demostraram que o tratamento com progesterona leva ao aumento dos níveis gênicos e proteicos das ADAMTSs -1 e -4 nas linhagens de câncer de ovário NIH-OVCAR-3 e ES-2 (Lima, M. A. et al., 2016). Além disso, a progesterona reduz a capacidade migratória e invasiva das células NIH-OVCAR-3 e ES-2 quando comparada as células controle (dados do 
nosso laboratório não publicados). A progesterona já mostrou estar envolvida com a redução da migração de mastócitos humanos (Belot et al., 2007) e de células da linhagem HUVEC, neste último caso, através da supressão da atividade de Rho mediada pela ativação de cSrc, efeito que foi bloqueado pelo pré-tratamento com o antagonista do receptor de progesterona, RU486, sugerindo que a inibição da migração induzida pela progesterona na HUVEC ocorre através da via de sinalização mediada pelo receptor deste hormônio (Lee et al., 2015).

Já foi relatado que ADAMTS-1 é capaz de se ligar ao fator de crescimento endotelial vascular (VEGF) (Iruela-Arispe et al., 2003). A matriz extracelular enriquecida por ADAMTS-1 acaba por sequestrar o fator de crescimento VEGF, impedindo que esse fator se ligue ao seu receptor presente na célula, levando a diminuição nas taxas de migração e invasão celular (Freitas et al., 2013). Esses fatores de crescimento e proteínas da matriz extracelular, ativam diferentes vias de sinalização que podem regular a formação de processos ricos em actina associados à migração celular. Estes processos biológicos são regulados por GTPases Rho (Ras-Homology GTPases) que ciclam entre uma forma ativa ligada ao GTP e uma forma inativa ligada ao GDP (Cerione and Zheng, 1996).

A progesterona poderia estar induzindo a diminuição da migração e invasão celular pelo aumento da expressão de ADAMTS-1 ou através de alterações na via das GTPAses Rho, e nosso objetivo neste trabalho foi investigar por qual mecanismo a progesterona leva a diminuição da invasão e migração das células $\mathrm{CHO}$, NIH-OVCAR-3 e ES-2 e se a protease estudada está envolvida neste processo.

\section{REVISÃO DE LITERATURA}

Na revisão de literatura, abordaremos os seguintes temas relacionados a esta tese: 1) Conceitos sobre o câncer e seu microambiente e a descrição destes no câncer de ovário; 2) ADAMTSs e uma descrição mais detalhada sobre a ADAMTS-1; 3) Hormônios sexuais e a progesterona; 4) Migração celular e as Rho GTPases, com enfoque para Cdc42; e 5) Os modelos celulares utilizados neste trabalho. 


\subsection{Câncer e seu microambiente}

O câncer é a principal causa de morte nos países economicamente desenvolvidos e a segunda principal causa de morte nos países em desenvolvimento. A incidência do câncer está aumentando nos países em desenvolvimento econômico, como resultado do envelhecimento da população e a adoção de estilos de vida associados com o desenvolvimento do câncer, incluindo tabagismo, falta de atividade física e dietas não balanceadas (Jemal et al., 2011), sendo que no Brasil, estimou-se quase 600 mil novos casos de câncer para o ano de 2019 (Inca, 2017). Nos adultos entre 35 e 70 anos, o câncer representa a $2^{\circ}$ causa de morte nos países de média e baixa renda, estando atrás somente das doenças cardiovasculares. Nos países mais ricos já é considerado a doença mais letal (Dagenais et al., 2019). O câncer é uma doença multifacetada caracterizada por alterações genéticas heterogêneas (Gerdes et al., 2014). Células normais evoluem progressivamente para um estado neoplásico ao adquirirem uma sucessão de capacidades que thes permitam evoluir para um fenótipo maligno. Até o momento, seis características principais mostraram estar envolvidas com o desenvolvimento do câncer, sendo elas: autossuficiência de sinais de crescimento; insensibilidade a sinais inibidores de crescimento; aumento do potencial de replicação; evasão à apoptose; sustentação da angiogênese; invasão do tecido e metástase (Hanahan and Weinberg, 2011).

Nenhuma célula normal possui a capacidade de proliferar na ausência de sinais estimuladores de crescimento. As células neoplásicas tornam-se independentes desta estimulação de crescimento exógena através da produção de fatores de crescimento, os quais irão agir sobre seus receptores, gerando um estímulo proliferativo autócrino (Cheng et al., 2008), hiperexpressão de receptores em sua superfície (Hanahan and Weinberg, 2000; 2011) ou através do envio de sinais a células normais, que respondem as células tumorais, fornecendo-as fatores de crescimento (Bhowmick et al., 2004). Para a proliferação contínua das células cancerígenas é igualmente necessário que elas evitem a ação dos inibidores de crescimento celular, os quais são essenciais para a homeostasia celular em tecidos normais. Defeitos nestes mecanismos de 
controle do crescimento celular, por feedback negativo, permitem aumentar a sinalização da proliferação (Hanahan and Weinberg, 2000; 2011).

As células dos mamíferos possuem um programa intrínseco que limita o seu potencial replicativo. $\mathrm{O}$ aparato molecular que limita o número de divisões está relacionado com segmentos de DNA nas extremidades dos cromossomos conhecidos como telômeros. Para a progressão tumoral é fundamental que a célula possua potencial replicativo ilimitado. Células malignas mostraram expressão de telomerase, o qual adiciona repetições de hexanucleotídeos aos locais terminais do DNA telomérico, evitando o encurtamento dos telômeros após cada ciclo celular, estabilizando o genoma mutante e conferindo a capacidade ilimitada de replicação (Raynaud et al., 2010).

A capacidade de uma população de células neoplásicas expandir em número não depende só da taxa de proliferação celular, mas também da taxa de morte celular (ou apoptose). A apoptose trata-se de uma morte programada e ativa, que requer energia, síntese e degradação proteica (Wyllie et al., 1980). Através dela, os organismos vivos eliminam as células potencialmente prejudiciais para a manutenção da homeostase (Hengartner, 2000). A resistência à apoptose pelas células neoplásicas pode ser adquirida por vários mecanismos, no entanto, o mais comum consiste em mutações no gene supressor tumoral p53, um gene chave na manutenção da integridade do DNA e na indução da cascata apoptótica (Harris, 1996; Hanahan and Weinberg, 2000; 2011).

Para que uma população de células consiga se estabelecer e sobreviva no tecido, elas necessitam fundamentalmente do oxigênio e de nutrientes fornecidos pelos vasos sanguíneos (Hanahan and Weinberg, 2000; 2011), desta maneira a angiogênese é fundamental para a formação do tumor. Nesse sentido, à medida que os tumores crescem, através da rápida proliferação de células tumorais, eles exigem a formação de uma nova vasculatura que irriga as células (Magalhães and Dias, 2019). Durante a tumorigênese o equilíbrio adequado entre moléculas pro-angiogênicas e anti-angiogênicas e a estimulação por fatores de crescimento parácrinos e autócrinos é perdida (Mueller and Fusenig, 2004). O mecanismo principal para a angiogênese, conhecido como a germinação endotelial (formação de vasos a partir de um vaso já existente), depende do aumento na regulação do fator de crescimento endotelial vascular e do desenvolvimento de interações entre as células endoteliais, pericitos, células 
estromais, e a associação com a MEC (Gordon et al., 2010). O fator de crescimento endotelial vascular (VEGF) é a principal molécula sinalizadora que regula a angiogênese, embora existam vários outros estímulos pró e antiangiogênicos. Nos tumores, devido ao desequilíbrio de tais estímulos, a angiogênese é anormal, resultando em uma rede vascular desorganizada e com vazamento (Magalhães and Dias, 2019)

A capacidade das células cancerígenas de migrar e invadir os tecidos circundantes com metástases subseqüentes para vários órgãos é uma das características da progressão do câncer e permite a essas células escaparem ao tumor primário e colonizarem novos locais do organismo (Santibanez et al., 2018). Na transição do carcinoma in situ para carcinoma invasivo há o rompimento da membrana basal, pela proliferação de células neoplásicas que possuem elevada capacidade proteolítica. Assim, a travessia das células neoplásicas pelas barreiras da membrana basal é resultado da síntese de proteases ativas e a aquisição de um fenótipo invasivo (Christofori, 2006). Várias classes de proteínas estão alteradas nas células com capacidade de invadir e metastizar, entre as quais as proteínas de adesão célula-célula, como as caderinas, as proteínas que ligam as células a substratos da matriz extracelular, como as integrinas (Cavallaro and Christofori, 2004) e proteínas secretadas, como as metaloproteinases de matriz (MMPs) (Roy et al., 2019).

Porém, a biologia dos tumores não se define simplesmente pelas diversas características que as células cancerosas adquirem, mas também abrange contribuições do microambiente tumoral para o processo de tumorigênese (Kalluri, 2003; Lili et al., 2013). O microambiente tumoral representa um nicho complexo onde células neoplásicas e não neoplásicas, fatores solúveis, moléculas de sinalização e componentes da MEC cooperativamente interagem e modulam eventos celulares relacionados à progressão tumoral (Rowe and Weiss, 2008; Catalano et al., 2013), auxiliando na transformação neoplásica, proteção do tumor do sistema imune, auxílio no crescimento do câncer e favorecimento na invasão e metástase tumoral (Keller and Li, 2011; Hanahan and Coussens, 2012; Swartz et al., 2012; Gkretsi et al., 2015) (Figura 1). 


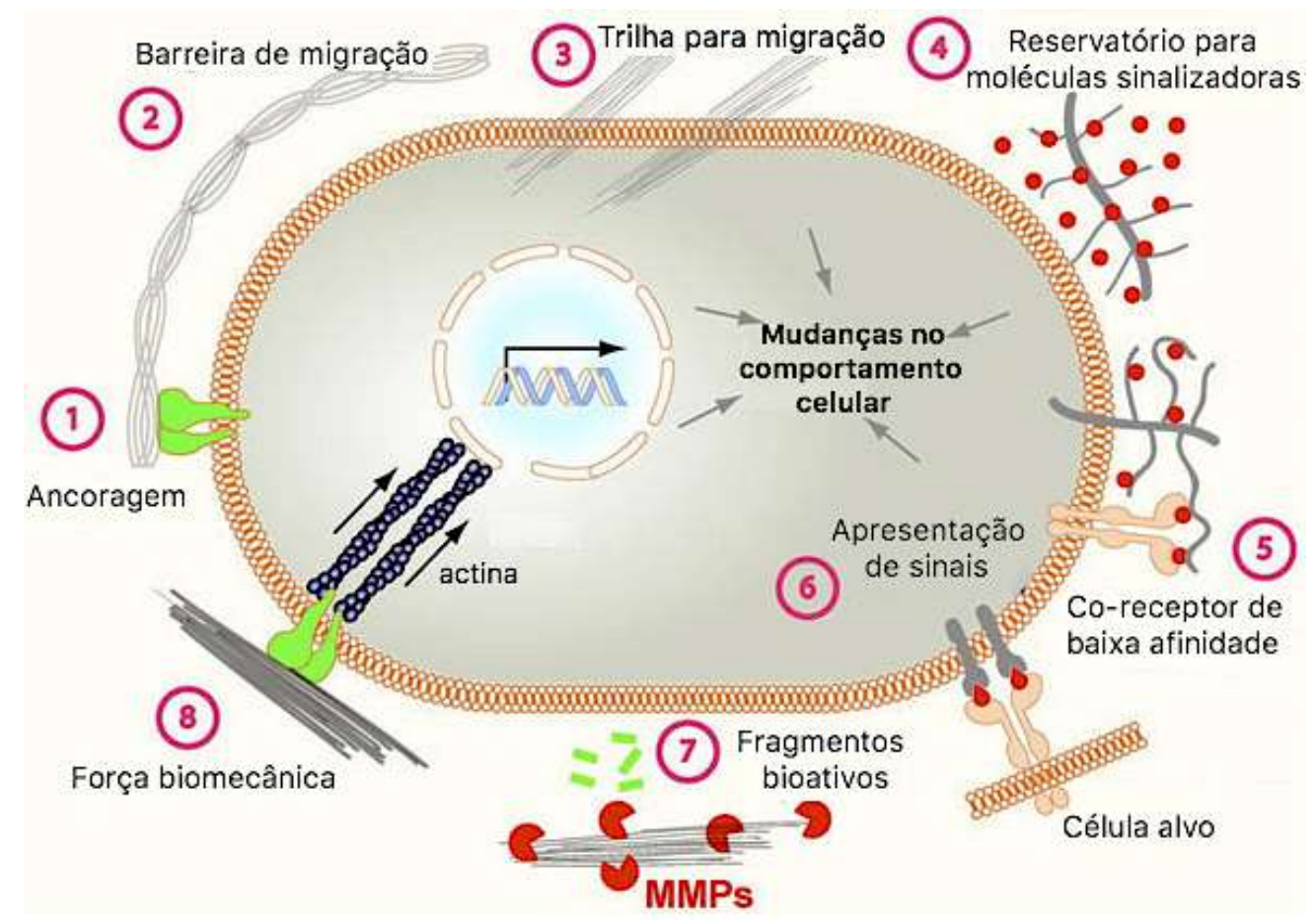

Figura 1. Mecanismos de função da MEC.

Ancoragem à membrana basal (fase 1). Barreira contra o movimento bloqueando a migração celular (fase 2). Caminho que facilita a migração celular (fase 3). Reservatório de moléculas (fase 4). Co-receptor de sinais (fase 5) ou apresentador de sinais (fase 6). Liberação de fragmentos bioativos (fase 7). Alterações no comportamento celular devido a modificações nos componentes da MEC (fase 8). Adaptado de (Lu et al., 2012)

Elementos celulares do estroma, incluindo fibroblastos associados ao câncer, propiciam uma rede de comunicação essencial, via secreção de fatores de crescimento e quimiocinas, induzindo alterações na MEC, proporcionando assim sinais oncogênicos adicionais que aumentam a vascularização, proliferação e invasão tumoral (Kalluri and Zeisberg, 2006). Alterações nos componentes moleculares e na dinâmica da MEC já foram descritos em diversas doenças e são uma marca registrada no desenvolvimento do câncer. Por exemplo, o excesso ou a diminuição na produção dos componentes da MEC são proeminentes na fibrose do tecido de muitos órgãos (Frantz et al., 2010) e vários colágenos mostraram aumento na deposição durante a formação do tumor (Kauppila et al., 1998; Huijbers et al., 2010). Além disso, moléculas da MEC e seus receptores, como proteoglicanos de sulfato de heparan e CD44, que facilitam a sinalização de fatores de crescimento, frequentemente são produzidas em excesso no câncer (Nasser, 2008). A expressão alterada de 
integrina é freqüentemente detectada em tumores, onde as integrinas têm papel no apoio à sinalização do receptor do fator de crescimento oncogênico (GFR) e na migração e invasão de células cancerígenas dependentes de GFR. Além disso, as integrinas determinam a colonização de locais metastáticos e facilitam a sobrevivência independente de ancoragem das células tumorais circulantes. Além disso as integrinas interagem com diversas moléculas da superfície celular, incluindo canais, receptores e proteínas secretadas que constituem novas vias de promoção de tumores. A ativação de vias de sinalização mediada por integrina, o endurecimento e a remodelação do estroma do tumor são etapas fundamentais na progressão do câncer, apoiando a invasão, a aquisição das características das células-tronco do câncer e a resistência a medicamentos (Hamidi and Ivaska, 2018).

Por outro lado, as células tumorais secretam diretamente uma variedade de proteínas, que incluem fatores de crescimento, moléculas de adesão e proteinases, que degradam ou induzem o recrutamento de biomoléculas que são hábeis na degradação da MEC, e estas estão envolvidas na adesão celular, motilidade, comunicação intercelular e invasão (Handsley and Edwards, 2005; Mbeunkui and Johann, 2009; Silva et al., 2016). Ao mesmo tempo, componentes da MEC podem se ligar as moléculas de sinalização impedindo a sua difusão livre; atuando como um dissipador para estes sinais, ajudando a formar gradientes de concentração. Alguns componentes da MEC, como os proteoglicanos, podem se ligar seletivamente a diferentes fatores de crescimento funcionando assim como co-receptores e apresentadores de sinais (Norton et al., 2005; Hynes, 2009; Lu et al., 2011). A MEC também pode iniciar diretamente eventos de sinalização, liberando fragmentos bioativos, os quais foram processados por proteases, como as MMPs (Hynes, 2009; Lu et al., 2011). As MMPs exercem sua atividade proteolítica e degradam as barreiras físicas, facilitando a angiogênese, a invasão de células tumorais e a metástase. $O$ crescimento tumoral e a angiogênese também dependem do aumento da disponibilidade de moléculas de sinalização, como fatores de crescimento e citocinas, promovido pelas MMPs, tornando esses fatores mais acessíveis às células cancerosas e ao microambiente tumoral. Isto ocorre libertando-os da MEC ou da superfície celular. As MMPs também modulam as interações célulacélula e célula-MEC pelo processamento da E-caderina e das integrinas, 
respectivamente, afetando o fenótipo das células, promovendo a transição epitelio-mesenquimal, e aumentando a migração celular (Gialeli et al., 2011).

\subsection{Ovários, câncer de ovário e seu micoambiente}

As glândulas de produção dos hormônios femininos são os ovários. As mulheres têm dois ovários, um de cada lado da pelve, em contato com o útero através das trompas. Sua função é armazenar os ovócitos e produzir o estrogênio e a progesterona, que, entre outras coisas, regem o ciclo menstrual da mulher. Os ovócitos são liberados dos ovários a cada ciclo menstrual normal e se encaminham para o útero pelas trompas. O óvulo se fixa na parede interna do útero e se desenvolve num feto depois de fertilizado pelo espermatozóide.

Os ovários na sua camada mais externa são revestidos por epitélio cúbico simples, o qual é sustentado por uma camada de tecido conjuntivo denso denominado de túnica albugínea. Os gametas femininos, ou ovócitos, localizamse no interior dos folículos ovarianos que estão presentes na região cortical do ovário. A parte mais interna do ovário é a região medular, formada por tecido conjuntivo frouxo com um rico leito vascular (Junqueira and Carneiro, 2017). O folículo ovariano é a unidade morfofuncional do ovário, sendo constituído por um oócito circundado por células somáticas (granulosa e tecais). A função do folículo é proporcionar um ambiente ideal para a manutenção da viabilidade, crescimento e maturação do oócito (Picton et al., 2008).

Ambos os tumores, benignos e malignos, podem surgir de cada um dos três tipos de células ovarianas, que compreendem, as células germinativas, epiteliais e do estroma. A maioria dos tumores de ovário tem origem epitelial (mais de $80 \%$ ); 10 a $15 \%$ são tumores de células germinativas e 5 a $10 \%$, tumores do estroma. Entre os tumores epiteliais, $40 \%$ são do tipo seroso, seguidos pelos tumores mucinosos, endometrioides, de células claras e mistos (Chen et al., 2003). Os tumores malignos podem ser classificados em quatro estádios: I, II, III e IV. No estádio I, o câncer encontra-se somente em um ou ambos os ovários. No II, ocorre disseminação para órgãos próximos dentro da pelve, tais como, útero, bexiga, cólon sigmoide ou reto. Já no estádio III, ocorre a disseminação para órgãos de dentro da pelve e para linfonodos retroperitoniais, além da possibilidade de ocorrer a disseminação para órgãos 
distantes. No estádio IV, a forma mais avançada, o mesmo encontra-se em fluídos pulmonares, sendo denominado de derrame pleural maligno, podendo ou não ocorrer a disseminação para o interior do baço, fígado, gânglios linfáticos diferentes dos linfonodos retroperitoniais e outros órgãos ou tecidos fora da cavidade peritoneal (American_Cancer_Society, 2018)

Devido à localização dos ovários, aos sintomas inespecíficos e a falta de biomarcadores para a detecção precoce, mais de $80 \%$ das mulheres apresentam a doença na forma avançada (estadios III e IV) quando diagnosticadas, e mesmo com tratamento, a taxa de sobrevida em cinco anos das pacientes com carcinoma de ovário é apenas de 30-50\%. Este prognóstico pobre é resultado do diagnóstico tardio e da terapia ineficaz para a doença em estágio avançado (Ween et al., 2011; Jayson et al., 2014), tornando este carcinoma a principal causa de morte neoplásica ginecológica no mundo, representando cerca de $2,5 \%$ de todas as doenças malignas em mulheres, e responsável por $5 \%$ de todas as mortes relacionadas ao câncer em mulheres (Sapoznik et al., 2009; Bray et al., 2018). Embora a incidência de câncer de ovário tenha diminuído nas últimas décadas, o resultado clínico ainda está longe de ser aceitável (Henderson et al., 2018). No Brasil, segundo o instituto Nacional de Câncer, estimou-se 6.150 novos casos de câncer de ovário, para cada ano do biênio 2018-2019, com um risco estimado de 5,79 casos a cada 100 mil e o oitavo mais incidente (Inca, 2017).

Os fatores de risco mais comuns associados ao câncer de ovário são a idade, histórico familiar e exposição hormonal (Ristow et al., 2006; Gates et al., 2010). O câncer de ovário é raro em mulheres com idade abaixo dos 40 anos, sendo que o risco é aumentado após está idade, com maiores incidências entre 65 e 79 anos (Adami et al., 2008). Além disso, este tipo de tumor pode estar relacionado ao histórico familiar de carcinoma da mama, ovário ou ambos e nessas pacientes pode incidir em idade mais precoce do que em população geral. Essa síndrome familiar está relacionada à mutação, principalmente, em dois genes, o BRCA-1 e BRCA-2, envolvidos no processo de reparo de DNA (Cannistra, 2004). Mutações nas células do ovário também podem ser ocasionadas pela exposição a hormonios sexuais; estudos mostram que 0 tratamento de reposição hormonal, tanto o com a utilização somente de estrogênio ou com o uso combinado deste com progestina, aumenta o risco em 
desenvolver tumores malignos no ovário (Pearce et al., 2009). Além disso, o estímulo repetido de gonadotrofinas e estrogênio sobre o epitélio da superfície do ovário durante a vida fértil da mulher, também está relacionado a danos no DNA, o que poderia levar ao carcinoma (Fathalla, 2013)

Por outro lado, alguns fatores estão relacionados com uma menor incidência deste tumor, como gestação, amamentação, uso de contraceptivos orais ou ter realizado ligadura tubária ou histerectomia (Ricci et al., 2008). Durante a gestação ocorrem anovulação e supressão pituitária e, logo, há diminuição no risco carcinogênico sobre epitélio ovariano. Assim, teoricamente, cada gestação adicional está associada com diminuição de risco de carcinoma de ovário (Jeppsson et al., 1977; Schock et al., 2014). Torna-se difícil avaliar o fator protetor da amamentação isoladamente, uma vez que está relacionada à gestação. Assim, muitos estudos são favoráveis ao seu papel protetor (Riman et al., 2002; Tung et al., 2003; Chiaffarino et al., 2005). Contraceptivos hormonais são um fator de proteção estabelecido para o câncer de ovário. Uma reanálise de 45 estudos distintos realizados em 21 países mostrou que quanto mais tempo uma mulher usa anticoncepcionais hormonais, menor o risco de se desenvolver esta neoplasia (Beral et al., 2008). Ligação tubária e histerectomia, com conservação de ovários, podem comprometer o suplemento sanguíneo ovariano. Com isso, as sequelas cirúrgicas desses procedimentos, inclusive as circulatórias, agem diminuindo a ação hormonal e, assim, reduzem o risco de câncer de ovário em torno de 80\% (Riman et al., 2004).

As funções desempenhadas pela MEC ovariana estão intimamente relacionadas com a sua diversidade de compartimentos e componentes. Dentre os principais compartimentos, têm a lâmina basal folicular, o fluído folicular, a zona pelúcida, e o estroma ovariano. Em cada um deles, existem diferentes componentes encontrados de maneira difusa pelo tecido ovariano, como a fibronectina, colágeno, ácido hialurônico, versican (Rodgers et al., 2000) e proteases como ADAMTS's (a disintegrin and metalloproteinase with thrombospondin motifs) (Shozu et al., 2005). A MEC ovariana é importante para a sobrevivência e proliferação das células da granulosa durante a foliculogênese. In vitro, vários estudos têm demonstrado que a presença de componentes da MEC como o colágeno tipo IV, laminina e fibronectina melhoram a proliferação de células da granulosa, aumenta o número de folículos primordiais que entram 
na fase de crescimento, bem como influenciam a ação dos fatores de crescimento necessários para o desenvolvimento folicular (Woodruff and Shea, 2007). Proteases que compõem a MEC, como proteases da família ADAMTS já mostraram ser fundamentais para o processo de foliculogênese, além de desempenhar papel na formação de novos vasos linfáticos no estroma ovariano (Shozu et al., 2005; Brown et al., 2006).

No câncer de ovário alterações nos componentes da MEC mostraram estar relacionados com características mais malignas das células neoplásicas. Níveis elevados de laminina-y2, colágenos tipos I e III, fibronectina, sindecam-1, glipicano-1, versicam, e ácido hialurônico e seus receptores CD44 têm sido associados a um mau prognóstico para o câncer de ovário (Ricciardelli and Rodgers, 2006; Salani et al., 2007; Januchowski et al., 2014). As metaloproteinases, presentes nesse estroma, que degradam a matriz extracelular, são essenciais para a progressão tumoral e processo metastático (Rocks, Paulissen, Quesada-Calvo, et al., 2008). Já foi visto que os passos iniciais para que as células de câncer de ovário sofram metástase ocorre através da clivagem de vitronectina e fibronectina mediada pela metaloproteinase de matriz MMP-2 (Kenny et al., 2008).

Células estromais, como os fibroblastos, alteram as propriedades físicas do tumor por meio de deposição excessiva e remodelação aberrante da matriz extracelular, aumentando assim a formação de uma barreira intersticial que bloqueia a entrega eficiente de drogas (Sun, 2015). Foi identificado também que o nicho mesotelial do tumor de câncer de ovário seroso de alto grau é hipóxico, e a sinalização hipóxica melhora a deposição de colágeno do tipo I pelas células mesoteliais. Especificamente, a sinalização hipóxica aumentou a expressão da lisil oxidase (LOX) em células cancerígenas mesoteliais e ovarianas para promover a reticulação de colágeno e a invasão de células tumorais (Natarajan et al., 2019) No entanto, estudos mostraram que as mutações nas proteases ADAMTS, em pacientes com câncer de ovário, estavam significativamente correlacionados com uma melhor sensibilidade à quimioterapia e exibiram uma duração na resposta ao tratamento com quimioterapicos significativamente mais longa do que aqueles com tumores que exibiam a forma não mutata de ADAMTS (Yuexin Liu et al., 2015), demonstrando, dessa forma, o papel de molélculas da MEC na regressão do câncer 
Outro processo extracelular que partipa na evolução do câncer de ovário é a angiogenêse. Entre os reguladores conhecidos da angiogênese estão fatores de crescimento, metaloproteinases da matriz, citocinas e integrinas. Um participante chave no desenvolvimento da rede vascular patológica do tumor é o fator de crescimento endotelial vascular (VEGF) e sua via de sinalização. No câncer epitelial de ovário, o aumento da expressão de VEGF tem um valor prognóstico: está relacionado ao grau do tumor, estágio da doença e sobrevida dos pacientes. Como os receptores VEGF estão presentes na superfície das células cancerígenas do ovário, parece que o VEGF pode desempenhar um papel único no desenvolvimento dessa neoplasia. Ao aumentar a permeabilidade vascular no peritônio, o VEGF também é responsável pela formação de líquido ascítico em pacientes com câncer de ovário. Consequentemente, a inibição da angiogênese patológica tornou-se uma das novas opções terapêuticas amplamente testadas no tratamento do câncer de ovário (Cortez et al., 2018).

O desenvolvimento e manutenção do câncer de ovário também está envolvida com o papel dos hormônios sexuais e embora seja bem aceito que as células epiteliais de câncer ovariano sejam responsivas à estimulação de hormônios esteróides, novos estudos apresentam as pistas de que o estroma ovariano também pode ter um papel ativo nesse processo. Por exemplo, componentes celulares do estroma ovariano imediatamente adjacente aos focos do tumor pode expressar marcadores ligados à diferenciação associada aos hormônios sexuais esteróidais e esteroidogênese, juntamente com enzimas esteróides, enquanto o epitélio expressa receptores hormonais correspondentes (Blanco et al., 2017).

\subsection{ADAMTS's e ADAMTS-1}

As ADAMTSs (adisintegrin and metalloproteinase with thrombospondin motifs ou adamalysin-thrombospondin) são enzimas semelhantes as MMP's dependentes de $\mathrm{Zn}^{2+} / \mathrm{Ca}^{2+}$ (Porter et al., 2005) secretadas e que estão envolvidas em diversas funções, como o processamento de colágeno, clivagem dos proteoglicanos da matriz (versican, agrecan e brevican), angiogênese (Vázquez, Hastings, et al., 1999; Stanton et al., 2011), clivagem da protease do fator de Von Willebrand para a homeostase da coagulação sanguínea, 
inflamação (Kuno et al., 1997; Apte, 2009), organogênese e fertilidade (Porter et al., 2005; Rocks, Paulissen, El Hour, et al., 2008), estrutura do tecido conjuntivo e câncer (Le Goff and Cormier-Daire, 2011). Independente do substrato que degradam, as ADAMTS's apresentam algumas similaridades estruturais. De um modo geral, elas constituem-se de um peptídeo sinal, um pró-domínio auto inibitório (domínio pró-peptídico), um domínio catalítico e um domínio hemopexina (Figura 2). É no domínio metaloproteinase, que segue imediatamente o pró-domínio, que é o ponto da organização estrutural onde se iniciam as diferenças entre as famílias de metaloproteinases (Niewiarowski et al., 1994). O domínio catalítico possui um elevado grau de homologia entre as diferentes ADAMTSs, e contém a sequência de ligação ao zinco HEXXHXXGXXH, na qual o zinco catalítico é coordenado pelos três resíduos de histidina (Gomis-Rüth, 2009; Tallant et al., 2010). O domínio desintegrina-like localiza-se em estreita proximidade com o sítio ativo, e funciona provavelmente regulando a atividade da enzima, fornecendo substrato auxiliar de ligação à superfície (Gerhardt et al., 2007; Mosyak et al., 2008). O domínio rico em cisteína e a região espaçadora, determinam o reconhecimento e a ligação da protease aos substratos, assim como a sua localização na MEC (Gendron et al., 2007; Fushimi et al., 2008). O domínio trombospondina (TSP) central é altamente conservado entre todas as ADAMTSs. Os domínios TSP adicionais (que variam em quantidade entre os membros da família ADAMTS) presentes na região Cterminal da protease, atuam juntamente com o domínio desintegrina, para manter a protease em uma localização apropriada na MEC e para o correto reconhecimento dos substratos (Stanton et al., 2011). A família ADAMTS, é geralmente subdividida em quatro classes, baseada nas similaridades estruturais e/ou funcionais: proteoglicanases (ADAMTS -1, -4, -5, -8, - e -15), pró-colagenases-n-peptidases ( ADAMTS -2, -3 e -14), clivagem do fator de Von Willebrand (ADAMTS-13), e aquelas proteases que as funções permanecem indefinidas (Porter et al., 2005; Apte, 2009). 

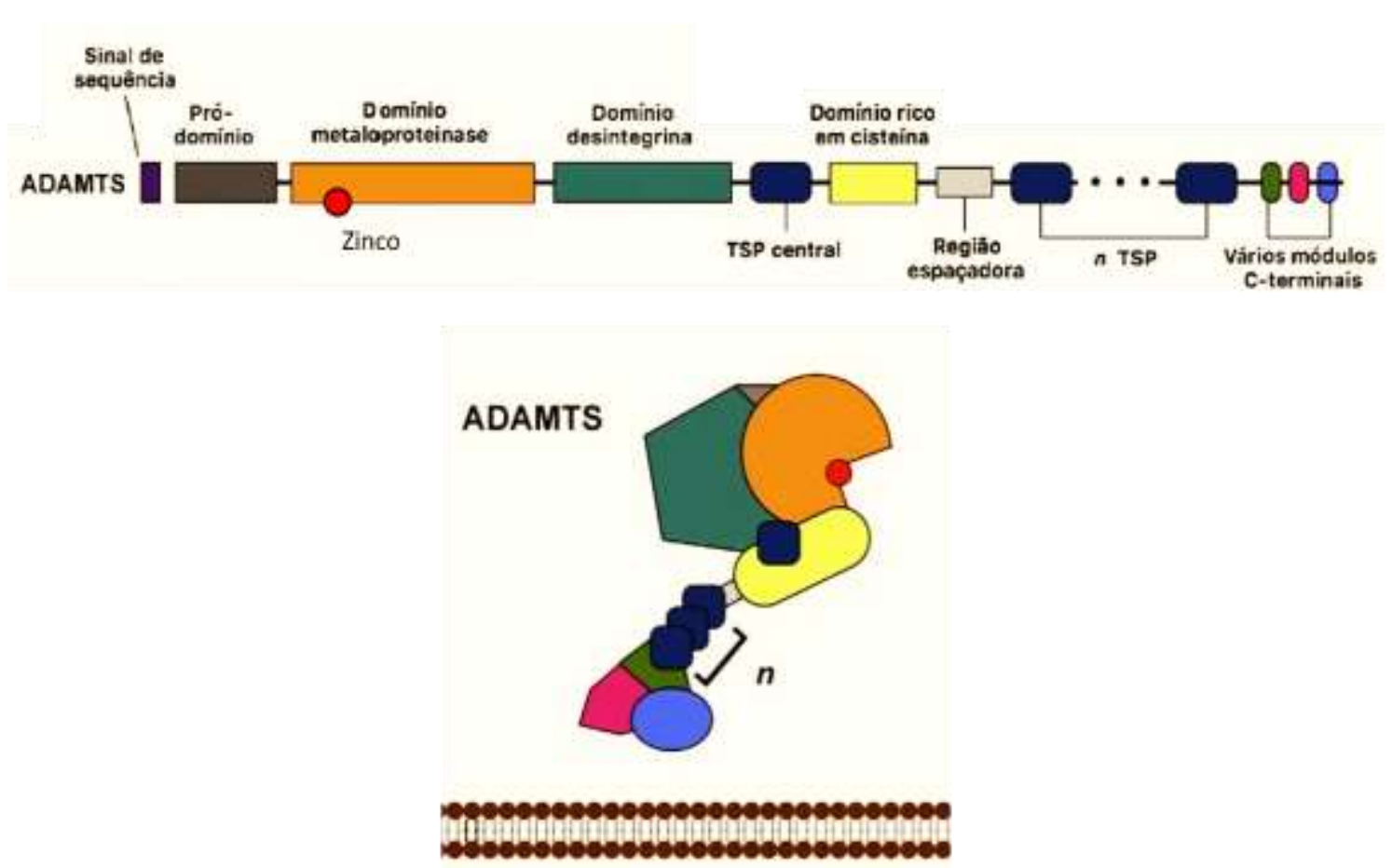

Figura 2. Representação esquemática das ADAMTSs.

Domínios estruturais das ADAMTSs. As ADAMTSs apresentam pró-domínios e domínios catalíticos, são metaloproteinases secretadas que não possuem domínios transmembrânicos e citoplasmáticos. Adaptado de (Yang et al., 2017)

Estas são secretadas na forma de precursores inativos (zimogênios) cuja latência é mantida através da interação entre o resíduo de cisteína, que está presente no pró-domínio, e o zinco presente no domínio catalítico, o que impede o acesso ao sítio ativo pelo substrato. Elas podem ser ativadas por MMPs, por outras classes de proteases, por meio da ação não proteolítica, como o estresse oxidativo e detergentes, ou através de auto-clivagem. Estes promovem a clivagem do domínio pró-peptídicos, deixando o sítio catalítico da enzima livre para interação com o respectivo substrato (Rozanov et al., 2004; Ra and Parks, 2007). As metaloproteinases, regulam uma variedade de processos fisiológicos e eventos de sinalização, e também desempenham importante função em processos patológicos, como na comunicação molecular entre o tumor e o estroma (Kessenbrock et al., 2010). Portanto, é necessário que haja um controle rígido das atividades das proteases, para evitar danos teciduais indesejáveis. Os inibidores teciduais de metaloproteinases (TIMPs) são inibidores endógenos das MMPs e promovem o controle da atividade dessas formando um complexo na 
proporção de 1 - 1 com o zinco do domínio catalítico, promovendo, assim, um impedimento estérico dessas com os seus substratos (Raffetto and Khalil, 2008). O equilíbrio tecidual entre MMPs e TIMPs é primordial para a dinâmica da degradação da matriz extracelular, sendo fundamental para a manutenção da homeostase tecidual, progressão do câncer e metástase (Devy et al., 2002; Hua et al., 2011).

Fisiologicamente ADAMTS-1 foi inicialmente descrita como um mediador da inflamação (Kuno et al., 1997), entretanto já foi demostrado que esta protease é necessária para o crescimento normal, além de auxiliar na estrutura e no funcionamento dos rins, da glândula adrenal e do aparelho reprodutor feminino (Shindo et al., 2000), participando da foliculogênese ovariana, na formação de vasos sanguíneos e linfáticos (Brown et al., 2006) e do processo de ovulação (Brown et al., 2010).

No ovário, durante o processo de ovulação induzido pelo hormônio luteinizante (LH), a libertação de um ovócito maduro com células do cumulus circundante através do epitélio superficial exige a remodelação da matriz extracelular ovariana (Nagase and Woessner, 1999). Estudos mostram que ADAMTS-1 é fundamental para a morfogênese estrutural dos folículos e do estroma ovariano, além de estar relacionado com o desenvolvimento da rede de drenagem linfática do ovário (Brown et al., 2006). Já foi demonstrado que o gene da ADAMTS-1 é exclusivamente expresso em células foliculares da granulosa no momento da ovulação, na matriz que circunda os folículos ovarianos (Espey et al., 2000; Richards et al., 2005) e que a indução de ADAMTS-1 é drasticamente reduzida, em ratos, quando a síntese de progesterona é inibida com epostano (agente antiprogesterona), bem como em ratos que não possuem receptor para progesterona (Robker et al., 2000). O padrão temporal da expressão deste gene, em conjunto com sua regulação pela progesterona, sugere que a metaloproteinase deste gene pode ter um papel importante no mecanismo de ovulação.

ADAMTS-1 é sintetizada como um pró-zimogênio e sofre glicosilação logo após a tradução da proteína. A secreção de ADAMTS-1 para a MEC requer a excisão desse pró-domínio da proteína madura de $87 \mathrm{kDa}$, por endopeptidases furina relacionadas. ADAMTS-1 pode ser processada e ser detectada como uma proteína de $65 \mathrm{kDa}$. A região C-terminal da protease madura liga-se diretamente 
na MEC e se associa com outras proteínas tais como fibulina-1, TGF- $\beta$ (fator de transformação do crescimento beta) latente e com proteoglicanos sulfatados. A protease catalisa a degradação do colágeno tipo I (Rehn et al., 2007), proteoglicanos do estroma de tecidos específicos, como o versicam (Russell et al., 2003; Ricciardelli et al., 2011), agrecam (Rodríguez-Manzaneque et al., 2002), sindecam-4 (Rodríguez-Manzaneque et al., 2009) e proteínas da membrana basal (nidogênio 1 e 2) (Canals et al., 2006; Tan et al., 2013). Assim, a estrutura complexa de ADAMTS-1 pode, portanto, influenciar o ambiente tumoral por uma série de vias (Tan et al., 2013) (Figura 3).

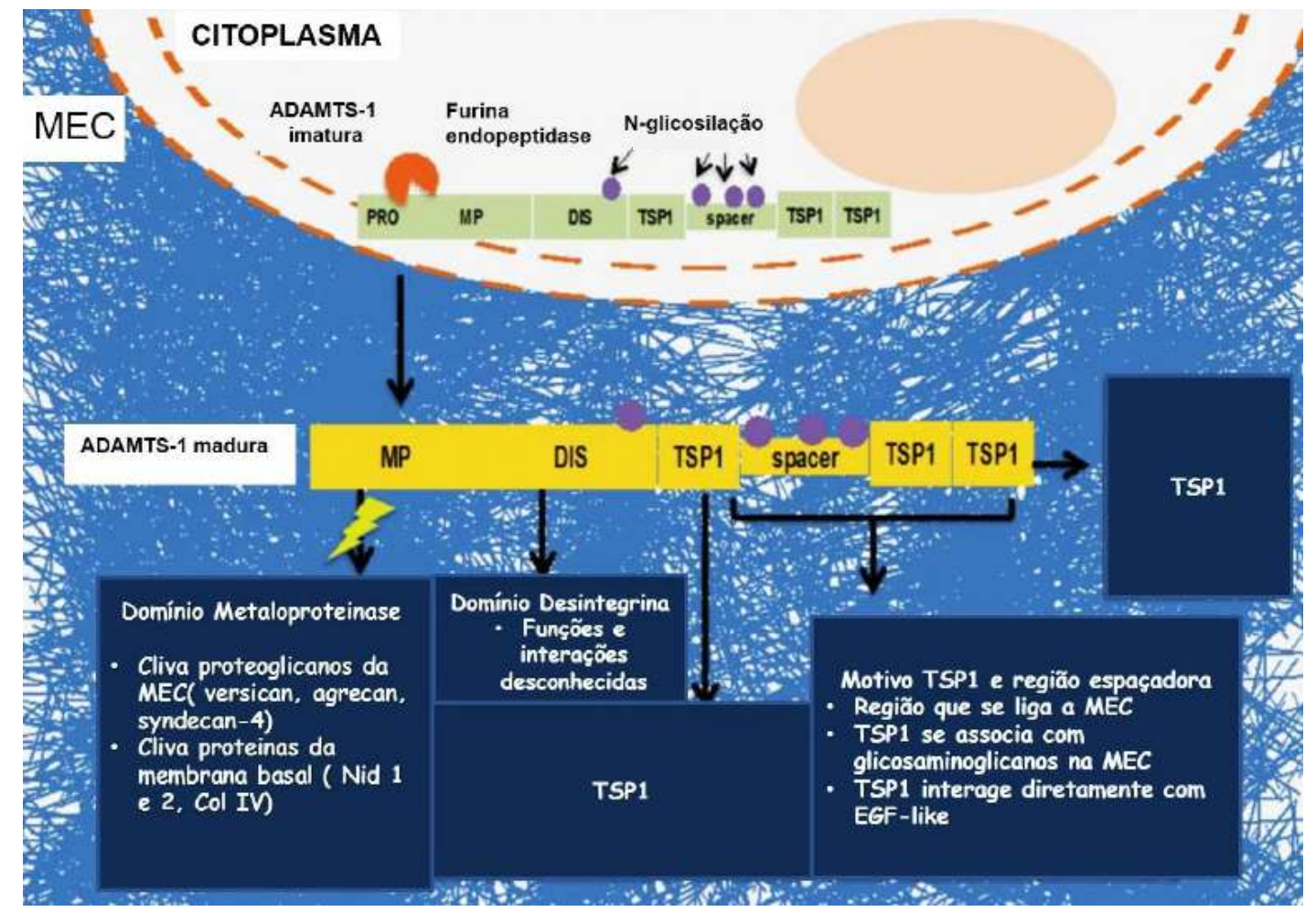

Figura 3. Síntese e função da protease ADAMTS-1.

A metade amino da ADAMTS-1 é composta pelos domínios: pró-domínio (PRO), metaloproteinase (MP) e desintegrina (DIS), enquanto a região carboxila da ADAMTS1 consiste em 3 motivos de Trombospondina do tipo 1 (TSP1) e uma região espaçadora. ADAMTS-1 é inicialmente sintetizada como um pró-zimogênio e sofre N-glicosilação pós-tradução. As endopeptidases da furina cortam o pró-domínio da ADAMTS1, após o qual a enzima madura é secretada na matriz extracelular, onde fica ligada à matriz pela sua região espaçadora. Na MEC, o domínio de metaloprotease catalítica da ADAMTS1 facilita a clivagem de proteoglicanos estromais (versican, aggrecans e syndecan-4), proteínas da membrana basal (nidogênio $1 / 2$ e colágeno tipo I) e proteínas TSP1. O domínio TSP1 interage diretamente com moléculas EGF-like (Tan et al., 2013). 
Em relação a sua função nos tumores, ADAMTS-1 possui efeito antiangiogênico (Vázquez, Hastings, et al., 1999; Iruela-Arispe et al., 2003; Lee et al., 2006), no entanto, alguns trabalhos mostram que ADAMTS-1 tem sua expressão aumentada em tumores de alto grau de malignidade (Masui et al., 2001), podendo promover a proliferação (Liu et al., 2006), sobrevivência (Ricciardelli et al., 2011), migração e invasão celular (Tyan et al., 2012), talvez devido a sua capacidade de degradar o agrecan e o versican, os quais são componentes da matriz extracelular que funcionam como barreira a passagem da células. Dados do nosso laboratório mostram que em tumores mais agressivos de mama, existe uma diminuição nos níveis de ADAMTS-1 quando comparados ao tecido normal (Freitas et al., 2013). Uma revisão da literatura mostra que o valor de expressão da proteína de ADAMTS-1 está reduzida em diferentes tipos de câncer, inclusive no câncer de ovário (Tan et al., 2013).

Liu et al., 2006 (Liu et al., 2006) demonstraram que a ADAMTS-1 sofre auto-clivagem proteolítica, e que a protease ADAMTS-1 sem clivagem e os seus fragmentos exibem atividade pro- e anti-tumoral, respectivamente. Observou-se também que a atividade de metaloproteinase ADAMTS-1 é necessária para o seu potencial pro-tumoral, favorecendo a metástase. Além disso, foi demonstrado que a atividade anti-tumoral dos fragmentos de ADAMTS-1 depende do motivo TSP-1, que é mascarado na molécula de comprimento total, indicando que o efeito de ADAMTS-1 sobre a metástase do tumor depende se a molécula está clivada ou intacta.

\subsection{Hormônios sexuais e a progesterona}

Hormônios esteroidais são moléculas regulatórias de natureza lipídica que atuam através de receptores localizados no núcleo das células alvo. Quando ocorre a ligação do hormônio ao seu receptor, este passa por uma mudança conformacional que o ativa, formando complexos e tornando-o capaz de promover ou inibir a transcrição de um grupo específico de genes (Alberts et al., 2002; Couse et al., 2006).

Os receptores de estrógeno (Era e $\operatorname{Er} \beta$ ) apresentam localização nuclear, assim como os receptores para andrógenos (AR), já os receptores de progesterona (PR) podem ter localização nuclear ou na membrana plasmática, 
e todos estes apresentam a estrutura clássica dos receptores de esteróides, composta por 4 domínios distintos: um domínio $\mathrm{N}$-terminal regulador da transcrição, um domínio de ligação ao DNA com os clássicos dedos de zinco proximal e distal, uma região "dobradiça" e um domínio de ligação ao seu respectivo hormônio (Mosselman et al., 1996; Couse et al., 2006).

Estes hormônios estão integrados em cada aspecto da fisiologia reprodutiva dos mamíferos, em ambos sexos, incluindo o desenvolvimento, gametogênese, função das gônodas, do controle hipotálamo - pituitária, comportamento sexual e maternal, gestação e lactação.

Os hormônios esteroidais são produzidos em tecidos específicos do corpo e são divididos em duas classes, os hormônios sexuais e progestacionais e os hormônios adrenais. O colesterol é o esteroide de maior prevalência no organismo e percussor, entre outros, de hormônios sexuais como os estrógenos e as progestinas (Litwack $G$ and $\mathrm{Tj}, 1998$ ).

Diferentes tipos de células do ovário sintetizam preferencialmente determinados hormônios sexuais, as células da teca, por exemplo, produzem principalmente a androstenediona, hormônio esteroide percussor do andrógeno testosterona e dos estrógenos estrona e estradiol. A progesterona é produzida principalmente pelas células que formam o corpo lúteo, glândula endócrina temporária formada após o processo de ovulação. O tipo de hormônio esteroide produzido pelas células também muda com sua progressiva maturação, as células da granulosa de folículos em crescimento secretam principalmente estradiol e pouca ou nenhuma progesterona, enquanto após a ovulação, as células da granulosa luteinizadas secretam principalmente progesterona (Peters and Mcnatty, 1980).

A mulher adulta é exposta continuamente a flutuações hormonais ao longo da vida, até a menopausa, como um resultado de ciclos reprodutivos, conhecidos como ciclos hormonais. Os ciclos são controlados pelo eixo hipotálamo - pituitária - ovário, onde o hipotálamo secreta gonadotropina, que agem na liberação de hormônios que estimulam o hormônio folículo-estimulante (FSH), que leva a produção do hormônio luteinizante (LH). Esses hormônios por sua vez, induzem a síntese de estrógeno e progesterona realizada pelos ovários (Hawkins and Matzuk, 2008). 
A progesterona e o estradiol são importantes reguladores dos processos de proliferação e diferenciação celular no trato genital feminino. Alterações da resposta destes hormônios podem estar relacionadas ao aparecimento de doenças estrogênio-dependentes como a endometriose, câncer de endométrio, infertilidade, câncer de mama e ovário (Romano et al., 2006).

No câncer os hormônios sexuais modulam a proliferação, apoptose, migração, metástase e angiogênese, influenciando desde o processo de tumorigênese, o crescimento celular e a metástase (Ramachandran, 2011). Os papeis dos hormônios no câncer de ovário incluem fatores de proteção e de risco para a doença. Contraceptivos hormonais são um fator de proteção estabelecido para o câncer de ovário. Uma reanálise de 45 estudos distintos realizados em 21 países mostrou que quanto mais tempo uma mulher usa anticoncepcionais hormonais, menor o risco de se desenvolver esta neoplasia (Beral et al., 2008). Estudos mostram que o tratamento de reposição hormonal, tanto o com a utilização somente de estrogênio, como o uso combinado deste com progestina, aumenta o risco em desenvolver câncer de ovário (Pearce et al., 2009).

A progesterona é produzida pelo corpo lúteo, uma estrutura glandular transitória, que inicia seu desenvolvimento no ovário imediatamente após a ovulação, e esta relacionada com a preparação do útero para a aceitação do embrião, à preparação das mamas para a secreção láctea, o crescimento folicular, a ovulação e a luteinização (Schams and Berisha, 2002).

A progesterona ou respostas celulares a este hormônio parecem oferecer proteção contra o desenvolvimento do câncer de ovário (Ho, 2003). A progesterona protege as células da hiperestimulação estrogênica, pois diminui o número de receptores para o estrógeno, aumenta seu metabolismo intracelular e inibe a conversão da androstenediona em estrona, reduzindo a atividade mitótica das células (Voigt et al., 1991). Deficiências de progesterona, devido à menopausa, a infertilidade ou alterações no gene de PR estão associados com um risco aumentado de câncer de ovário (Edmondson and Monaghan, 2001; Syed et al., 2001). Estudos clínicos têm demonstrado que a multiparidade, a gravidez de gêmeos, e a gravidez que ocorre na vida adulta aumentam drasticamente os níveis de progesterona em circulação e reduzem o risco de desenvolver câncer de ovário (Adami et al., 1994; Banks et al., 1997). Além disso, já foi observado que a expressão de receptores para progesterona estão 
relacionados com um melhor prognóstico em mulheres com câncer de ovário (Lee et al., 2005; Lenhard et al., 2012). O uso de contraceptivo oral hormonal tem sido consistentemente associado a uma redução no risco de desenvolvimento do câncer de ovário (Beral et al., 2008; Diep et al., 2015). Já foi observado que formulações de contraceptivos orais com altos níveis de progesterona estão associadas a um menor risco de câncer de ovário do que as formulações com baixos níveis de progestina (Schildkraut et al., 2002). No entanto, acredita-se que a maior parte dos efeitos protetores da progesterona são mediados pelo receptor da progesterona nuclear (n-Pr), os quais se perdem progressivamente com o aumento do grau de malignidade do câncer de ovário (Akahira et al., 2002).

Por outro lado, estudos demonstraram que a progesterona pode inibir a invasão e migração de células de câncer de mama, mediadas pela desfosforilação das cinases. Essa inibição parece ser independente da presença ou ausência de PR nas células de câncer de mama, demostrando que este hormônio pode agir por diferentes meios de modo anti-tumorigênico (Godbole et al., 2017).

\subsection{Migração celular e Rho GTPases}

A migração celular é essencial para o desenvolvimento de animais multicelulares. Durante o desenvolvimento, algumas populações de células migram longas distâncias, por exemplo, as células da crista neural migram por todo o embrião para formar diferentes tipos de células, como melanócitos, músculo liso vascular e células de Schwann (Mayor and Theveneau, 2013). A migração celular também contribui para a progressão da maioria das doenças humanas. As células cancerígenas migram para os linfonodos ou vasos sanguíneos para formar metástases (Spano et al., 2012), enquanto a migração das células imunes é central para doenças autoimunes e inflamação crônica (Griffith and Luster, 2013).

Nos últimos anos, ficou claro que as células são altamente flexíveis na maneira como migram e podem mudar rapidamente entre os diferentes modos de migração. As células podem migrar como células únicas ou coletivamente como grupos (Friedl et al., 2012; De Pascalis and Etienne-Manneville, 2017) 
dependendo da rigidez e composição de seu ambiente, incluindo componentes da matriz extracelular e células circundantes (Paluch and Raz, 2013). As interações célula-célula afetam fortemente como as células se movem e o que regula sua migração. Quando uma célula encontra outra célula, elas freqüentemente param de migrar em um processo chamado inibição de contato e formam aderências célula-célula ou mudam de direção, levando à dispersão celular in vivo (Batson et al., 2013). As células podem ser guiadas em direção a um local específico por sinais solúveis ou associados à matriz, ou aparentemente podem migrar aleatoriamente com frequentes mudanças de direção (Graziano and Weiner, 2014). O que é comum a todos esses modos de migração é o envolvimento das Rho GTPases. Foi demonstrado que membros da família Rho de pequenas GTPases desempenham papéis essenciais na migração e invasão celular através da regulação de processos como: lamelipódios, filopódios, aderências célula-célula, aderências célula-matriz extracelular, bolhas de membrana e/ou invadopodios, atuando em locais e tempos específicos nas células (Fritz and Pertz, 2016).

GTPases são interruptores moleculares que utilizam uma estratégia bioquímica simples para controlar os processos celulares complexos. Cerca de 20 proteínas Rho foram identificadas e classificadas em cinco subgrupos, de acordo com sua sequência primária e suas funções conhecidas: Rho-like, Raclike, Cdc42-like, Rnd e RhoBTB (Burridge and Wennerberg, 2004; Lawson and Ridley, 2018). As proteínas Rho ciclam entre uma forma ativa ligada ao GTP (Guanosine-5'-triphosphate) e uma forma inativa ligada ao GDP (Guanosine diphosphate). Esse ciclo é regulado por Guanine Nucleotide Exchange Factors (GEFs), que estimulam a troca do GDP pelo GTP e por GTPase-activating Proteins (GAPs), que catalizam a hidrólise do GTP e, consequentemente, inativam as proteínas Rho (Cerione and Zheng, 1996; Hodge and Ridley, 2016) (Figura 4). GTPases Rho medeiam a indução de protuberâncias da membrana, como filopódios (Cdc42, Rhod, Rif, Wrch-1, ou CHAP) e lamelipódios (Rac1, Rac2, RAC3, RhoG) (Aspenström et al., 2004). RhoA, B e C, estimulam a formação de fibras de stress e adesões focais (Wheeler and Ridley, 2004), enquanto Rnd1, Rnd2, RND3 / Rhoe e Wrch-1, por outro lado, afetam negativamente fibras de stress (Aspenström et al., 2004). Além disso, as GTPases Rho, como CDC42, controlam a direção da migração das células 
(Etienne-Manneville et al., 2005). A conclusão de que Rho, Rac e Cdc42 regulam três vias de transdução de sinal separadas que ligam receptores de membrana plasmática à montagem de estruturas de actina filamentosas distintas foi confirmada em uma ampla variedade de tipos de células de mamíferos, bem como em leveduras, moscas e vermes.

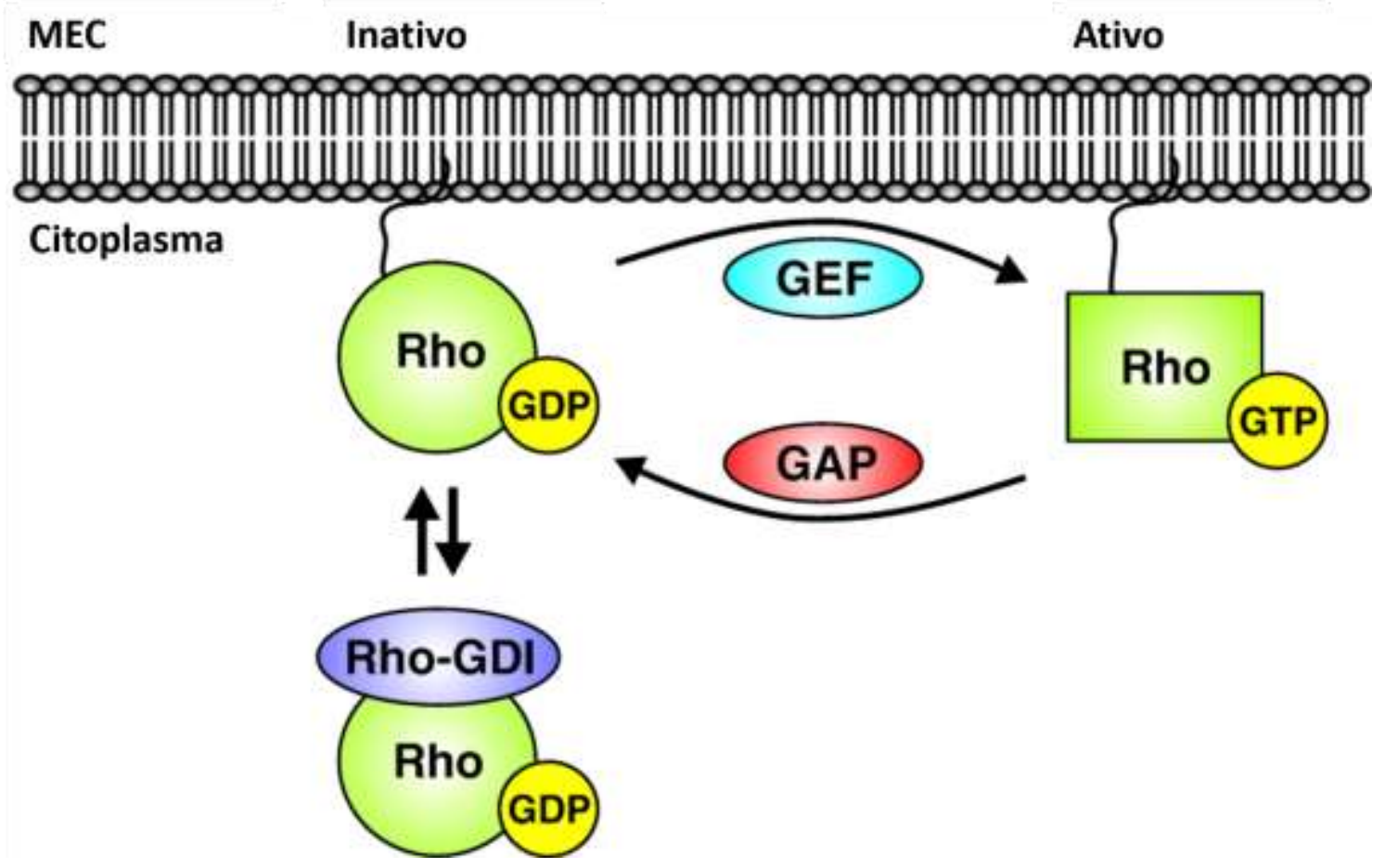

Figura 4. Regulação da atividade das Rho-GTPases.

Modelo que descreve como as Rho-GTPases são reguladas. Os inibidores de dissociação Rho-GDP (Rho-GDIs) sequestram Rho-GTPases inativas ligadas ao GDP (Rho) no citoplasma. Quando liberadas de Rho-GDIs, as Rho-GTPases são direcionadas para a membrana plasmática, onde seu ciclo de ativação é regulado por GEFs que promovem a carga de GTP e a ativação de Rho-GTPases. A inativação de Rho-GTPases é mediada por GAPs que promovem a hidrólise de GTP ao GDP. Adaptado de (Huveneers and Danen, 2009)

Um interesse adicional nas Rho GTPases foi alimentado pela constatação de que elas regulam muitas outras vias de transdução de sinal além daquelas ligadas ao citoesqueleto de actina. Elas participam da regulação da polaridade celular, transcrição gênica, progressão do ciclo celular G1, dinâmica dos 
microtúbulos, vias de transporte vesicular e uma variedade de atividades enzimáticas (Etienne-Manneville and Hall, 2002).

Cdc42 desempenha um papel importante no estabelecimento da polaridade migratória celular e persistência migratória, atuando através do complexo de polaridade Par, parte da maquinaria molecular que regula a polaridade celular e mantém uma homeostase celular normal (Aranda et al., 2008), bem como através de outros alvos. A análise genética de leveduras em brotamento forneceu a primeira evidência ligando Cdc42 à polaridade celular (Pruyne and Bretscher, 2000). Na ausência desta GTPase, a levedura Saccharomyces cerevisiae não pode estabelecer um local definido para o crescimento de células filhas e, como conseqüência, as células se expandiram isotropicamente. Da mesma forma, durante o acasalamento, as células de levedura estendem saliências na superfície direcionadas ao longo de um gradiente de feromônio secretado; sem Cdc42p (Cdc42 das leveduras) as saliências não são mais orientadas corretamente.

Das pequenas GTPases Rho, Cdc42 emergiu como um regulador crítico da polaridade celular e da migração celular direcionada. Como mostrado pela primeira vez em células não neuronais, o Cdc42 funciona como um regulador crítico da polaridade celular, orientação dos centrossomas, formação de junções célula-célula e dinâmica da actina em células móveis in vivo (Heasman and Ridley, 2008). Estudos recentes demonstraram que Cdc42 está envolvido na histogênese cerebelar, incluindo padronização de axônios, migração guiada pela glia e foliação do córtex cerebelar. Em cada estágio do desenvolvimento, a ausência de Cdc42 resultou em defeitos na polaridade neuronal e nas interações neurônio-gliais (Govek et al., 2018). A conclusão é clara: Cdc42 não é necessário para o crescimento celular ou a formação de protrusões, mas é necessário para que esses processos ocorram no lugar certo na superfície celular.

A capacidade de uma célula se mover requer a organização assimétrica das atividades celulares. A frente da célula em migração gera força protrusiva, geralmente associada à extensão de um lamelipódio na direção da migração, juntamente com o desenvolvimento de novas adesões celulares ao substrato extracelular. Isso, por si só, não é suficiente para a migração celular, desta maneira, a contratilidade celular é necessária para permitir que o corpo e a parte traseira da célula sigam a frente da célula, que se estende. Através de sua 
capacidade de promover protrusão e contração celular, acredita-se que o citoesqueleto de actina forneça a força motriz da migração celular (EtienneManneville and Hall, 2002). A migração celular é normalmente direcionada e controlada por sinais extracelulares. Na cultura de tecidos, muitas células podem adotar uma morfologia polarizada entre a frente e a retaguarda sendo capazes de migrar, mas isso é apenas transitoriamente sustentado. A estabilização do movimento direcional, requer informações de pistas externas, e isso é controlado por Cdc42. Estudos demonstraram que em células de macrófagos quando o Cdc42 é inibido, o macrófago inicia uma caminhada aleatória, sendo esta GTPase responsável, por tanto, pela direcionalidade da célula (Allen et al., 1998).

No câncer de ovário observou-se que os níveis de Rac1 e Cdc42 estimulam a adesão, invasão e metástase de células cancerígenas. Utilizando vários ensaios para avaliar a dependência do comportamento das células cancerígenas de ovário em Rac1 e Cdc42, como câmaras de invasão Matrigel e o tratamento de múltiplas linhagens celulares de câncer de ovário com inibidores específicos de Rac1 e Cdc42, foi observado uma significativa redução na invasão celular. Esses dados demonstram que Rac1 e Cdc42 são importantes no desenvolvimento do câncer de ovário invasivo e metastático e podem ser estudados como novos alvos terapêuticos na redução da metástase da doença (Hudson et al., 2018).

Desta maneira, Cdc42 é uma Rho GTPase importante para a polaridade e direcionalidade celular durante o processo de migração e sua atividade pode ser controlada por diferentes moléculas em situações fisiológicas e patológicas.

\subsection{Modelo utilizado}

Linhagens celulares derivadas de tumores são os modelos mais utilizados em pesquisa sobre o câncer (Domcke et al., 2013), pois essas amostras patológicas mimetizam o estado real do tumor in vivo e muitas vezes proporcionam resultados reprodutíveis, que fornecem informações para a compreensão da biologia dos tumores e aplicação na clínica médica (Van Staveren et al., 2009). 
No presente estudo, utilizamos linhagens de ovário comerciais, com diferentes graus de malignidade. A linhagem $\mathrm{CHO}$, derivado de células normais de hamster chinês, a NIH-OVCAR-3 com fenótipo maligno menos agressivo e mais diferenciado e a linhagem ES-2 com fenótipo agressivo.

A linhagem de células $\mathrm{CHO}$ é originalmente derivada de ovário de hamster chinês e tornou-se uma fonte básica de células devido ao seu crescimento robusto como células aderentes ou em suspensão. Elas são passíveis de modificações genéticas e métodos para transfecção de células, expressão de proteínas recombinantes e seleção de clones são bem caracterizados. As células $\mathrm{CHO}$ também podem sofrer modificações pós-traducionais compatíveis com humanos, tornando-as ideais para aplicações terapêuticas e farmacêuticas, como a fabricação de proteínas. As células $\mathrm{CHO}$ não possuem capacidade de síntese de prolina e não expressam EGFR. Várias linhagens celulares variantes emergiram da $\mathrm{CHO}$, como o $\mathrm{CHO}-\mathrm{K} 1$, que não possui atividade de di-hidrofolato redutase (DHFR) (Baumann et al., 2017). As células $\mathrm{CHO}$ não contem receptores clássicos de progesterona (Bishop, 2013).

Adenocarcinoma é um tipo de câncer que se forma nas glândulas secretoras de muco ao longo do corpo. A linhagem NIH-OVCAR-3 foi estabelecida a partir de ascites malignas, de uma mulher caucasiana de 60 anos de idade com adenocarcinoma de ovário progressivo, após a quimioterapia de combinação com ciclofosfamida, adriamicina e cisplatina. A linhagem cresce em monocamada e é tumorigênica em ratos atímicos (Hamilton et al., 1983). Esta linhagem possui receptores para estrógeno, progesterona e andrógenos (Collection, 2014b).

Carcinoma de células claras (CCC) do ovário é um subtipo de câncer epitelial de ovário conhecido por sua relativa resistência à quimioterapia baseada em platina e de prognóstico ruim (Kwok et al., 2014). ES-2 é uma linhagem de CCC humana estabelecida em 1980 a partir de uma amostra de tumor cirúrgico retirado de uma mulher negra de 47 anos. O tumor foi descrito como um carcinoma de células de ovário pouco diferenciado. Inicialmente, as células foram cultivadas em ágar macio, um indicador de transformação e tumorigenicidade. As células exibem uma baixa a moderada resistência para um número de agentes quimioterapêuticos, incluindo doxorrubicina, cisplatina, carmustina, etoposido e ciano morfolino doxorrubicina (Collection, 2014a). Esta 
linhagem celular não possui receptores para estrogênio (ER -) (Halon et al., 2011) e receptores nucleares de progesterona (n-PR -); e possui receptores de membrana para a progesterona $(m-P R+)$ (Charles et al., 2010).

\section{CONCLUSÃO}

Baseado nos nossos resultados, concluímos que:

- A progesterona aumenta os níveis da protease ADAMTS-1 no lisado celular e no meio condicionado de células de ovário;

- A progesterona nas concentrações de $500 \mathrm{nM}$ e $1 \mu \mathrm{M}$ diminui a migração e invasão das células CHO, NIH-OVCAR-3 e ES-2 sem alterar a viabilidade, este efeito é recuperado quando na utilização do antagonista do receptor de progesterona, RU486;

- A progesterona não induz a diminuição na migração celular quando ADAMTS-1 é deletado;

- O aumento de ADAMTS-1 ao meio condicionado das células de ovário diminui a migração e invasão celular mas não potencializa os efeitos da progesterona;

- O tratamento com a progesterona ou o meio enriquecido com ADAMTS1 leva a uma diminuição na polarização celular;

- A deleção de ADAMTS-1, mas não o tratamento com $1 \mu \mathrm{M}$ de progesterona aumenta os níveis e modula a atividade de Cdc42 na linhagem de câncer de ovário ES-2, conferindo uma melhor polaridade e direcionalidade durante a migração celular;

- O tratamento com progesterona diminui a fosforilação de FAK e Src;

- A ausência de ADAMTS-1 permite o crescimento mais coeso de esferas na ausência de adesão celular. 


\section{REFERÊNCIAS *}

ADAMI, H. O. et al. Parity, age at first childbirth, and risk of ovarian cancer. Lancet, v. 344, n. 8932, p. 1250-4, Nov 1994. ISSN 0140-6736. Available at: < http://www.ncbi.nlm.nih.gov/pubmed/7967985 >.

ADAMI, H. O.; HUNTER, D.; TRICHOUPOULOS, D. Textbook of Cancer Epidemiology. Oxford: Oxford 2008.

AKAHIRA, J. et al. Differential expression of progesterone receptor isoforms A and $B$ in the normal ovary, and in benign, borderline, and malignant ovarian tumors. Jpn J Cancer Res, v. 93, n. 7, p. 807-15, Jul 2002. ISSN 0910-5050. Available at: < http://www.ncbi.nlm.nih.gov/pubmed/12149147 >.

ALBERTS, B. et al. Molecular Biology of the Cell. New York: Garland Science, 2002. ISBN 0-8153-3218-1.

ALLEN, W. E. et al. A role for Cdc42 in macrophage chemotaxis. J Cell Biol, v. 141 , n. 5, p. 1147-57, Jun 1998. ISSN 0021-9525. Available at: < https://www.ncbi.nlm.nih.gov/pubmed/9606207 >.

AMERICAN_CANCER_SOCIETY. Ovarian Cancer 2018.

APTE, S. S. A disintegrin-like and metalloprotease (reprolysin type) with thrombospondin type 1 motifs: the ADAMTS family. Int J Biochem Cell Biol, v. 36 , n. 6, p. 981-5, Jun 2004. ISSN 1357-2725. Available at: < http://www.ncbi.nlm.nih.gov/pubmed/15094112 >.

A disintegrin-like and metalloprotease (reprolysin-type) with thrombospondin type 1 motif (ADAMTS) superfamily: functions and mechanisms. J Biol Chem, v. 284, n. 46, p. 31493-7, Nov 2009. ISSN 1083-351X. Available at: $<$ http://www.ncbi.nlm.nih.gov/pubmed/19734141 >.

ARANDA, V.; NOLAN, M. E.; MUTHUSWAMY, S. K. Par complex in cancer: a regulator of normal cell polarity joins the dark side. Oncogene, v. 27, n. 55, p. 6878-87, Nov 2008. ISSN 1476-5594. Available at: < https://www.ncbi.nlm.nih.gov/pubmed/19029931 >.

ASPENSTRÖM, P.; FRANSSON, A.; SARAS, J. Rho GTPases have diverse effects on the organization of the actin filament system. Biochem J, v. 377, n. Pt 2 , p. 327-37, Jan 2004. ISSN 1470-8728. Available at: < http://www.ncbi.nlm.nih.gov/pubmed/14521508 >.

BANKS, E.; BERAL, V.; REEVES, G. The epidemiology of epithelial ovarian cancer: a review. International Journal of Gynecological Cancer, v. 7, n. 6, p. 425-438, 1997. Available at: < http://onlinelibrary.wiley.com/doi/10.1046/j.15251438.1997.09756.x >.

* De acordo com: ASSOCIAÇÃO BRASILEIRA DE NORMAS TÉCNICAS. NBR 6023: informação e documentação: referências: elaboração. Rio de Janeiro, 2002. 
BATSON, J.; ASTIN, J. W.; NOBES, C. D. Regulation of contact inhibition of locomotion by Eph-ephrin signalling. J Microsc, v. 251, n. 3, p. 232-41, Sep

ISSN $1365-2818$ Available at: https://www.ncbi.nlm.nih.gov/pubmed/23495724 >.

BAUMANN, M. et al. Preselection of recombinant gene integration sites enabling high transcription rates in $\mathrm{CHO}$ cells using alternate start codons and recombinase mediated cassette exchange. Biotechnol Bioeng, v. 114, n. 11, p. 2616-2627, 11 2017. ISSN 1097-0290. Available at: < https://www.ncbi.nlm.nih.gov/pubmed/28734047 >.

BELLANCE, C. et al. Progesterone receptor isoforms PRA and PRB differentially contribute to breast cancer cell migration through interaction with focal adhesion kinase complexes. Mol Biol Cell, v. 24, n. 9, p. 1363-74, May 2013. ISSN 19394586. Available at: < https://www.ncbi.nlm.nih.gov/pubmed/23485561 >.

BELOT, M. P. et al. Progesterone reduces the migration of mast cells toward the chemokine stromal cell-derived factor-1/CXCL12 with an accompanying decrease in CXCR4 receptors. Am J Physiol Endocrinol Metab, v. 292, n. 5, p. E1410-7, May 2007. ISSN 0193-1849. Available at: < http://www.ncbi.nlm.nih.gov/pubmed/17468394 >.

BERAL, V. et al. Ovarian cancer and oral contraceptives: collaborative reanalysis of data from 45 epidemiological studies including 23,257 women with ovarian cancer and 87,303 controls. Lancet, v. 371, n. 9609, p. 303-14, Jan 2008. ISSN 1474-547X. Available at: < http://www.ncbi.nlm.nih.gov/pubmed/18294997 > .

BHOWMICK, N. A.; NEILSON, E. G.; MOSES, H. L. Stromal fibroblasts in cancer initiation and progression. Nature, v. 432, n. 7015, p. 332-7, Nov 2004. ISSN 1476-4687. Available at: < http://www.ncbi.nlm.nih.gov/pubmed/15549095 >.

BISCHOF, P.; MEISSER, A.; CAMPANA, A. Involvement of trophoblast in embryo implantation: regulation by paracrine factors. J Reprod Immunol, v. 39, n. 1-2, p. 167-77, Aug 1998. ISSN 0165-0378. Available at: < https://www.ncbi.nlm.nih.gov/pubmed/9786460 >.

BISHOP, C. V. Progesterone inhibition of oxytocin signaling in endometrium. Front Neurosci, v. 7, p. 138, 2013. ISSN 1662-4548. Available at: < https://www.ncbi.nlm.nih.gov/pubmed/23966904 >.

BLANCO, L. Z. et al. Steroid hormone synthesis by the ovarian stroma surrounding epithelial ovarian tumors: a potential mechanism in ovarian tumorigenesis. Mod Pathol, v. 30, n. 4, p. 563-576, 04 2017. ISSN 1530-0285. Available at: < https://www.ncbi.nlm.nih.gov/pubmed/28059101 >.

BOKHARI, A. A. et al. Progesterone inhibits endometrial cancer invasiveness by inhibiting the TGF $\beta$ pathway. Cancer Prev Res (Phila), v. 7, n. 10, p. 1045-55, Oct 2014. ISSN 1940-6215. Available at: < https://www.ncbi.nlm.nih.gov/pubmed/25070663 >. 
BOONYARATANAKORNKIT, V. et al. The role and mechanism of progesterone receptor activation of extra-nuclear signaling pathways in regulating gene transcription and cell cycle progression. Steroids, v. 73, n. 9-10, p. 922-8, Oct 2008. ISSN 0039-128X. Available at: < https://www.ncbi.nlm.nih.gov/pubmed/18321550 > .

BRAY, F. et al. Global cancer statistics 2018: GLOBOCAN estimates of incidence and mortality worldwide for 36 cancers in 185 countries. CA Cancer $\mathbf{J}$ Clin, v. 68, n. 6, p. 394-424, 11 2018. ISSN 1542-4863. Available at: < https://www.ncbi.nlm.nih.gov/pubmed/30207593 >.

BROWN, H. M. et al. ADAMTS1 cleavage of versican mediates essential structural remodeling of the ovarian follicle and cumulus-oocyte matrix during ovulation in mice. Biol Reprod, v. 83, n. 4, p. 549-57, Oct 2010. ISSN 1529-7268. Available at: $<$ http://www.ncbi.nlm.nih.gov/pubmed/20592310 $>$.

Requirement for ADAMTS-1 in extracellular matrix remodeling during ovarian folliculogenesis and lymphangiogenesis. Dev Biol, v. 300, n. 2, p. 699709, Dec 2006. ISSN 0012-1606. Available at: < http://www.ncbi.nlm.nih.gov/pubmed/17097630 >.

BURRIDGE, K.; WENNERBERG, K. Rho and Rac take center stage. Cell, v. 116, n. 2, p. 167-79, Jan 2004. ISSN 0092-8674. Available at: < https://www.ncbi.nlm.nih.gov/pubmed/14744429 >.

CALABRESI, P.; CHABNER, B. A. Antineoplastic agents. New York: Pergamon Press, p.1247-8. 1990

CANALS, F. et al. Identification of substrates of the extracellular protease ADAMTS1 by DIGE proteomic analysis. Proteomics, v. 6 Suppl 1, p. S28-35, Apr 2006. ISSN 1615-9861. Available at: < http://www.ncbi.nlm.nih.gov/pubmed/16511810 >.

CANIPARI, R. et al. Mouse ovarian granulosa cells produce urokinase-type plasminogen activator, whereas the corresponding rat cells produce tissue-type plasminogen activator. J Cell Biol, v. 105, n. 2, p. 977-81, Aug 1987. ISSN 00219525. Available at: < https://www.ncbi.nlm.nih.gov/pubmed/3040774 > .

CANNISTRA, S. A. Cancer of the ovary. N Engl J Med, v. 351, n. 24, p. 251929, Dec 2004. ISSN 1533-4406. Available at: < http://www.ncbi.nlm.nih.gov/pubmed/15590954 >.

CATALANO, $V$. et al. Tumor and its microenvironment: a synergistic interplay. Semin Cancer Biol, v. 23, n. 6 Pt B, p. 522-32, Dec 2013. ISSN 1096-3650. Available at: $<$ https://www.ncbi.nlm.nih.gov/pubmed/24012661 >.

CAVALLARO, U.; CHRISTOFORI, G. Cell adhesion and signalling by cadherins and Ig-CAMs in cancer. Nat Rev Cancer, v. 4, n. 2, p. 118-32, Feb 2004. ISSN 1474-175X. Available at: < http://www.ncbi.nlm.nih.gov/pubmed/14964308 >. 
CERIONE, R. A.; ZHENG, Y. The Dbl family of oncogenes. Curr Opin Cell Biol, v. 8, n. 2, p. 216-22, Apr 1996. ISSN 0955-0674. Available at: < https://www.ncbi.nlm.nih.gov/pubmed/8791419 >.

CHALBOS, D. et al. Estrogens stimulate cell proliferation and induce secretory proteins in a human breast cancer cell line (T47D). J Clin Endocrinol Metab, v. 55, n. 2, p. 276-83, Aug 1982. ISSN 0021-972X. Available at: < https://www.ncbi.nlm.nih.gov/pubmed/7045150 >.

CHARLES, N. J.; THOMAS, P.; LANGE, C. A. Expression of membrane progesterone receptors (mPR/PAQR) in ovarian cancer cells: implications for progesterone-induced signaling events. Horm Cancer, v. 1, n. 4, p. 167-76, Aug 2010. ISSN 1868-8500. Available at: < http://www.ncbi.nlm.nih.gov/pubmed/21761364 >.

CHEN, C. C.; HARDY, D. B.; MENDELSON, C. R. Progesterone receptor inhibits proliferation of human breast cancer cells via induction of MAPK phosphatase 1 (MKP-1/DUSP1). J Biol Chem, v. 286, n. 50, p. 43091-102, Dec 2011. ISSN 1083-351X. Available at: < https://www.ncbi.nlm.nih.gov/pubmed/22020934 > .

CHEN, V. W. et al. Pathology and classification of ovarian tumors. Cancer, v. 97, n. 10 Suppl, p. 2631-42, May 2003. ISSN 0008-543X. Available at: < http://www.ncbi.nlm.nih.gov/pubmed/12733128 >.

CHENG, N. et al. Transforming growth factor-beta signaling-deficient fibroblasts enhance hepatocyte growth factor signaling in mammary carcinoma cells to promote scattering and invasion. Mol Cancer Res, v. 6, n. 10, p. 1521-33, Oct 2008. ISSN 1541-7786. Available at: < http://www.ncbi.nlm.nih.gov/pubmed/18922968 >.

CHIAFFARINO, F. et al. Breastfeeding and the risk of epithelial ovarian cancer in an Italian population. Gynecol Oncol, v. 98, n. 2, p. 304-8, Aug 2005. ISSN 0090-8258. Available at: < http://www.ncbi.nlm.nih.gov/pubmed/15975644 >.

CHRISTOFORI, G. New signals from the invasive front. Nature, v. 441, n. 7092 , p. 444-50, May 2006. ISSN 1476-4687. Available at: < http://www.ncbi.nlm.nih.gov/pubmed/16724056 >.

COLLECTION, A. T. C. ES-2 (ATCC® CRL-1978 ${ }^{\mathrm{TM}}$ ). https://www.atcc.org/products/all/CRL-1978.aspx?slp=1\#characteristics, 2014a. Avaialble at: $<$ https://www.atcc.org/products/all/CRL1978.aspx?slp=1\#characteristics $>$.

. NIH:OVCAR-3 [OVCAR3] (ATCC® HTB-161 ${ }^{\mathrm{TM}}$ ). 2014b. Avaialble at: < http://www.atcc.org/products/all/HTB-161.aspx\#characteristics > .

CONG, L.; ZHANG, F. Genome engineering using CRISPR-Cas9 system. Methods Mol Biol, v. 1239, p. 197-217, 2015. ISSN 1940-6029. Available at: < https://www.ncbi.nlm.nih.gov/pubmed/25408407 >. 
CORTEZ, A. J. et al. Advances in ovarian cancer therapy. Cancer Chemother Pharmacol, v. 81, n. 1, p. 17-38, 01 2018. ISSN 1432-0843. Available at: < https://www.ncbi.nlm.nih.gov/pubmed/29249039 >.

COUSE, J. F.; HEWITT, S. C.; KORACH, K. S. Steroid Receptor in the Ovary and Uterus. Elsevier, p. 593-658, 2006. Available at: < http://www.ncbi.nlm.nih.gov/pubmed/2776699 >.

DAGENAIS, G. R. et al. Variations in common diseases, hospital admissions, and deaths in middle-aged adults in 21 countries from five continents (PURE): a prospective cohort study. Lancet, Sep 2019. ISSN 1474-547X. Available at: < https://www.ncbi.nlm.nih.gov/pubmed/31492501 >.

DAI, B. et al. Dual roles of progesterone in embryo implantation in mouse. Endocrine, v. 21, n. 2, p. 123-32, Jul 2003. ISSN 1355-008X. Available at: < https://www.ncbi.nlm.nih.gov/pubmed/12897374 >.

DE PASCALIS, C.; ETIENNE-MANNEVILLE, S. Single and collective cell migration: the mechanics of adhesions. Mol Biol Cell, v. 28, n. 14, p. 1833-1846, Jul 2017. ISSN 1939-4586. Available at: < https://www.ncbi.nlm.nih.gov/pubmed/28684609 >

DEVY, L. et al. The pro- or antiangiogenic effect of plasminogen activator inhibitor 1 is dose dependent. FASEB J, v. 16, n. 2, p. 147-54, Feb 2002. ISSN 1530-6860. Available at: < http://www.ncbi.nlm.nih.gov/pubmed/11818362 >.

DI RENZO, M. F. et al. Overexpression of the Met/HGF receptor in ovarian cancer. Int J Cancer, v. 58, n. 5, p. 658-62, Sep 1994. ISSN 0020-7136. Available at: < https://www.ncbi.nlm.nih.gov/pubmed/8077049 >.

DIEP, C. H. et al. Progesterone action in breast, uterine, and ovarian cancers. $\mathbf{J}$ Mol Endocrinol, v. 54, n. 2, p. R31-R53, Apr 2015. ISSN 1479-6813. Available at: $<$ http://www.ncbi.nlm.nih.gov/pubmed/25587053 > .

DOMCKE, S. et al. Evaluating cell lines as tumour models by comparison of genomic profiles. Nat Commun, v. 4, p. 2126, 2013. ISSN 2041-1723. Available at: $<$ http://www.ncbi.nlm.nih.gov/pubmed/23839242 > .

DUBAIL, J. et al. ADAMTS-2 functions as anti-angiogenic and anti-tumoral molecule independently of its catalytic activity. Cell Mol Life Sci, v. 67, n. 24, p. 4213-32, Dec 2010. ISSN 1420-9071. Available at: < https://www.ncbi.nlm.nih.gov/pubmed/20574651 >.

EDMONDSON, R. J.; MONAGHAN, J. M. The epidemiology of ovarian cancer. Int J Gynecol Cancer, v. 11, n. 6, p. 423-9, 2001 Nov-Dec 2001. ISSN 1048891X. Available at: < http://www.ncbi.nlm.nih.gov/pubmed/11906544 > .

ESPEY, L. L. et al. Ovarian expression of a disintegrin and metalloproteinase with thrombospondin motifs during ovulation in the gonadotropin-primed 
immature rat. Biol Reprod, v. 62, n. 4, p. 1090-5, Apr 2000. ISSN 0006-3363. Available at: < http://www.ncbi.nlm.nih.gov/pubmed/10727282 >.

ETIENNE-MANNEVILLE, S.; HALL, A. Rho GTPases in cell biology. Nature, v. 420, n. 6916, p. 629-35, Dec 2002. ISSN 0028-0836. Available at: < https://www.ncbi.nlm.nih.gov/pubmed/12478284 >.

ETIENNE-MANNEVILLE, S. et al. Cdc42 and Par6-PKCzeta regulate the spatially localized association of Dlg1 and APC to control cell polarization. J Cell Biol, v. 170, n. 6, p. 895-901, Sep 2005. ISSN 0021-9525. Available at: < http://www.ncbi.nlm.nih.gov/pubmed/16157700 >.

FATHALLA, M. F. Incessant ovulation and ovarian cancer - a hypothesis revisited. Facts Views Vis Obgyn, v. 5, n. 4, p. 292-7, 2013. ISSN 2032-0418. Available at: < https://www.ncbi.nlm.nih.gov/pubmed/24753957 >.

FRANTZ, C.; STEWART, K. M.; WEAVER, V. M. The extracellular matrix at a glance. J Cell Sci, v. 123, n. Pt 24, p. 4195-200, Dec 2010. ISSN 1477-9137. Available at: < http://www.ncbi.nlm.nih.gov/pubmed/21123617 > .

FREITAS, V. M. et al. Decreased expression of ADAMTS-1 in human breast tumors stimulates migration and invasion. Mol Cancer, v. 12, p. 2, 2013. ISSN 1476-4598. Available at: < http://www.ncbi.nlm.nih.gov/pubmed/23289900 > .

FRIEDL, P. et al. Classifying collective cancer cell invasion. Nat Cell Biol, v. 14, n. 8, p. 777-83, Aug 2012. ISSN 1476-4679. Available at: < https://www.ncbi.nlm.nih.gov/pubmed/22854810 >.

FRITZ, R. D.; PERTZ, O. The dynamics of spatio-temporal Rho GTPase signaling: formation of signaling patterns. F1000Res, v. 5, 2016. ISSN 20461402. Available at: < https://www.ncbi.nlm.nih.gov/pubmed/27158467 >.

FUSHIMI, K. et al. Functional differences of the catalytic and non-catalytic domains in human ADAMTS-4 and ADAMTS- 5 in aggrecanolytic activity. J Biol Chem, v. 283, n. 11, p. 6706-16, Mar 2008. ISSN 0021-9258. Available at: < http://www.ncbi.nlm.nih.gov/pubmed/18156631 >.

GATES, M. A. et al. Risk factors for epithelial ovarian cancer by histologic subtype. Am J Epidemiol, v. 171, n. 1, p. 45-53, Jan 2010. ISSN 1476-6256. Available at: < http://www.ncbi.nlm.nih.gov/pubmed/19910378 > .

GENDRON, C. et al. Proteolytic activities of human ADAMTS-5: comparative studies with ADAMTS-4. J Biol Chem, v. 282, n. 25, p. 18294-306, Jun 2007. ISSN 0021-9258. Available at: < http://www.ncbi.nlm.nih.gov/pubmed/17430884 $>$.

GERDES, M. J. et al. Emerging understanding of multiscale tumor heterogeneity. Front Oncol, v. 4, p. 366, 2014. ISSN 2234-943X. Available at: < http://www.ncbi.nlm.nih.gov/pubmed/25566504 >. 
GERHARDT, S. et al. Crystal structures of human ADAMTS-1 reveal a conserved catalytic domain and a disintegrin-like domain with a fold homologous to cysteine-rich domains. J Mol Biol, v. 373, n. 4, p. 891-902, Nov 2007. ISSN 0022-2836. Available at: < https://www.ncbi.nlm.nih.gov/pubmed/17897672 >.

GIALELI, C.; THEOCHARIS, A. D.; KARAMANOS, N. K. Roles of matrix metalloproteinases in cancer progression and their pharmacological targeting. FEBS J, v. 278, n. 1, p. 16-27, Jan 2011. ISSN 1742-4658. Available at: < https://www.ncbi.nlm.nih.gov/pubmed/21087457 >.

GKRETSI, V. et al. Remodeling Components of the Tumor Microenvironment to Enhance Cancer Therapy. Front Oncol, v. 5, p. 214, 2015. Available at: < https://www.ncbi.nlm.nih.gov/pubmed/26528429 $>$.

GODBOLE, M. et al. Progesterone suppresses the invasion and migration of breast cancer cells irrespective of their progesterone receptor status - a short report. Cell Oncol (Dordr), v. 40, n. 4, p. 411-417, Aug 2017. ISSN 2211-3436. Available at: < https://www.ncbi.nlm.nih.gov/pubmed/28653288 >.

GOLDMAN, S.; SHALEV, E. Difference in progesterone-receptor isoforms ratio between early and late first-trimester human trophoblast is associated with differential cell invasion and matrix metalloproteinase 2 expression. Biol Reprod, v. 74 , n. 1, p. 13-22, Jan 2006. ISSN 0006-3363. Available at: < https://www.ncbi.nlm.nih.gov/pubmed/16135696 >.

GOMIS-RÜTH, F. X. Catalytic domain architecture of metzincin metalloproteases. J Biol Chem, v. 284, n. 23, p. 15353-7, Jun 2009. ISSN 0021 9258. Available at: < https://www.ncbi.nlm.nih.gov/pubmed/19201757 > .

GONZÁLEZ-OROZCO, J. C. et al. Activation of membrane progesterone receptor-alpha increases proliferation, migration, and invasion of human glioblastoma cells. Mol Cell Endocrinol, v. 477, p. 81-89, 12 2018. ISSN 18728057. Available at: < https://www.ncbi.nlm.nih.gov/pubmed/29894708 > .

GORDON, M. S.; MENDELSON, D. S.; KATO, G. Tumor angiogenesis and novel antiangiogenic strategies. Int J Cancer, v. 126, n. 8, p. 1777-87, Apr 2010. ISSN 1097-0215. Available at: < http://www.ncbi.nlm.nih.gov/pubmed/19904748 >.

GOVEK, E. E. et al. Cdc42 Regulates Neuronal Polarity during Cerebellar Axon Formation and Glial-Guided Migration. iScience, v. 1, p. 35-48, Mar 2018. ISSN 2589-0042. Available at: < https://www.ncbi.nlm.nih.gov/pubmed/29888765 >

GOYENECHE, A. A.; SEIDEL, E. E.; TELLERIA, C. M. Growth inhibition induced by antiprogestins RU-38486, ORG-31710, and CDB-2914 in ovarian cancer cells involves inhibition of cyclin dependent kinase 2. Invest New Drugs, v. 30, n. 3, p. 967-80, Jun 2012. ISSN 1573-0646. Available at: < https://www.ncbi.nlm.nih.gov/pubmed/21424700 >.

GRAHAM, J. D.; CLARKE, C. L. Expression and transcriptional activity of progesterone receptor $A$ and progesterone receptor $B$ in mammalian cells. 
Breast Cancer Res, v. 4, n. 5, p. 187-90, 2002. ISSN 1465-5411. Available at: $<$ https://www.ncbi.nlm.nih.gov/pubmed/12223122 >.

GRAZIANO, B. R.; WEINER, O. D. Self-organization of protrusions and polarity during eukaryotic chemotaxis. Curr Opin Cell Biol, v. 30, p. 60-7, Oct 2014. ISSN 1879-0410. Available at: < https://www.ncbi.nlm.nih.gov/pubmed/24998184 >.

GRIFFITH, J. W.; LUSTER, A. D. Targeting cells in motion: migrating toward improved therapies. Eur J Immunol, v. 43, n. 6, p. 1430-5, Jun 2013. ISSN 15214141. Available at: < https://www.ncbi.nlm.nih.gov/pubmed/23580465 >.

GRINDSTAD, T. et al. Progesterone Receptors in Prostate Cancer: Progesterone receptor $B$ is the isoform associated with disease progression. Sci Rep, v. 8, n. 1, p. 11358, 07 2018. ISSN 2045-2322. Available at: < https://www.ncbi.nlm.nih.gov/pubmed/30054508 >.

GUIOCHON-MANTEL, A. et al. Nuclear localization signals also mediate the outward movement of proteins from the nucleus. Proc Natl Acad Sci U S A, v. 91, n. 15, p. 7179-83, Jul 1994. ISSN 0027-8424. Available at: < https://www.ncbi.nlm.nih.gov/pubmed/8041765 >.

HALON, A. et al. Estrogen receptor alpha expression in ovarian cancer predicts longer overall survival. Pathol Oncol Res, v. 17, n. 3, p. 511-8, Sep 2011. ISSN 1532-2807. Available at: < http://www.ncbi.nlm.nih.gov/pubmed/21207255 >.

HAMIDI, H.; IVASKA, J. Every step of the way: integrins in cancer progression and metastasis. Nat Rev Cancer, v. 18, n. 9, p. 533-548, 09 2018. ISSN 14741768. Available at: < https://www.ncbi.nlm.nih.gov/pubmed/30002479 $>$.

HAMILTON, T. C. et al. Characterization of a human ovarian carcinoma cell line (NIH:OVCAR-3) with androgen and estrogen receptors. Cancer Res, v. 43, n. 11 , p. 5379-89, Nov 1983. ISSN 0008-5472. Available at: < http://www.ncbi.nlm.nih.gov/pubmed/6604576 >

HANAHAN, D.; COUSSENS, L. M. Accessories to the crime: functions of cells recruited to the tumor microenvironment. Cancer Cell, v. 21, n. 3, p. 309-22, Mar 2012. ISSN 1878-3686. Available at: < https://www.ncbi.nlm.nih.gov/pubmed/22439926 >.

HANAHAN, D.; WEINBERG, R. A. The hallmarks of cancer. Cell, v. 100, n. 1, p. 57-70, Jan 2000. ISSN 0092-8674. Available at: < http://www.ncbi.nlm.nih.gov/pubmed/10647931 >.

. Hallmarks of cancer: the next generation. Cell, v. 144, n. 5, p. 646-74, Mar 2011. ISSN 1097-4172. Available at: < http://www.ncbi.nlm.nih.gov/pubmed/21376230 > . 
HANDSLEY, M. M.; EDWARDS, D. R. Metalloproteinases and their inhibitors in tumor angiogenesis. Int J Cancer, v. 115, n. 6, p. 849-60, Jul 2005. ISSN 00207136. Available at: $<$ https://www.ncbi.nlm.nih.gov/pubmed/15729716 $>$.

HANNA, S. et al. A new genetically encoded single-chain biosensor for Cdc42 based on FRET, useful for live-cell imaging. PLoS One, v. 9, n. 5, p. e96469, 2014. ISSN 1932-6203. Available at: < https://www.ncbi.nlm.nih.gov/pubmed/24798463 >.

HARRIS, C. C. p53 tumor suppressor gene: from the basic research laboratory to the clinic--an abridged historical perspective. Carcinogenesis, v. 17, n. 6, p. 1187-98, Jun 1996. ISSN 0143-3334. Available at: < http://www.ncbi.nlm.nih.gov/pubmed/8681432 >.

HAWKINS, S. M.; MATZUK, M. M. The menstrual cycle: basic biology. Ann N Y Acad Sci, v. 1135 , p. 10-8, 2008. ISSN 0077-8923. Available at: < http://www.ncbi.nlm.nih.gov/pubmed/18574203 >.

HEASMAN, S. J.; RIDLEY, A. J. Mammalian Rho GTPases: new insights into their functions from in vivo studies. Nat Rev Mol Cell Biol, v. 9, n. 9, p. 690-701, Sep 2008. ISSN 1471-0080. Available at: < https://www.ncbi.nlm.nih.gov/pubmed/18719708 >.

HENDERSON, J. T.; WEBBER, E. M.; SAWAYA, G. F. Screening for Ovarian Cancer: Updated Evidence Report and Systematic Review for the US Preventive Services Task Force. JAMA, v. 319, n. 6, p. 595-606, 02 2018. ISSN 1538-3598. Available at: < https://www.ncbi.nlm.nih.gov/pubmed/29450530 > .

HENGARTNER, M. O. The biochemistry of apoptosis. Nature, v. 407, n. 6805, p. 770-6, Oct 2000. ISSN 0028-0836. Available at: < http://www.ncbi.nlm.nih.gov/pubmed/11048727 >.

HIGUCHI, T. et al. Induction of tissue inhibitor of metalloproteinase 3 gene expression during in vitro decidualization of human endometrial stromal cells. Endocrinology, v. 136, n. 11, p. 4973-81, Nov 1995. ISSN 0013-7227. Available at: < https://www.ncbi.nlm.nih.gov/pubmed/7588231 >.

HO, S. M. Estrogen, progesterone and epithelial ovarian cancer. Reprod Biol Endocrinol, v. 1, p. 73, Oct 2003. ISSN 1477-7827. Available at: < http://www.ncbi.nlm.nih.gov/pubmed/14577831 >.

HODGE, R. G.; RIDLEY, A. J. Regulating Rho GTPases and their regulators. Nat Rev Mol Cell Biol, v. 17, n. 8, p. 496-510, 08 2016. ISSN 1471-0080. Available at: $<$ https://www.ncbi.nlm.nih.gov/pubmed/27301673 > .

HODGSON, L.; PERTZ, O.; HAHN, K. M. Design and optimization of genetically encoded fluorescent biosensors: GTPase biosensors. Methods Cell Biol, v. 85, p. 63-81, 2008. ISSN 0091-679X. Available at: < https://www.ncbi.nlm.nih.gov/pubmed/18155459 >. 
HU, Z.; DENG, X. [The effect of progesterone on proliferation and apoptosis in ovarian cancer cell]. Zhonghua Fu Chan Ke Za Zhi, v. 35, n. 7, p. 423-6, Jul 2000. ISSN 0529-567X. Available at: < https://www.ncbi.nlm.nih.gov/pubmed/11776191 >.

HUA, $\mathrm{H}$. et al. Matrix metalloproteinases in tumorigenesis: an evolving paradigm. Cell Mol Life Sci, v. 68, n. 23, p. 3853-68, Dec 2011. ISSN 1420-9071. Available at: $<$ http://www.ncbi.nlm.nih.gov/pubmed/21744247 > .

HUDSON, L. G. et al. Ovarian Tumor Microenvironment Signaling: Convergence on the Rac1 GTPase. Cancers (Basel), v. 10, n. 10, Sep 2018. ISSN 2072-6694. Available at: < https://www.ncbi.nlm.nih.gov/pubmed/30261690 >.

HUIJBERS, I. J. et al. A role for fibrillar collagen deposition and the collagen internalization receptor endo180 in glioma invasion. PLoS One, v. 5, n. 3, p. e9808, 2010. ISSN 1932-6203. Available at: < http://www.ncbi.nlm.nih.gov/pubmed/20339555 >.

HUVENEERS, S.; DANEN, E. H. Adhesion signaling - crosstalk between integrins, Src and Rho. J Cell Sci, v. 122, n. Pt 8, p. 1059-69, Apr 2009. ISSN 0021-9533. Available at: < https://www.ncbi.nlm.nih.gov/pubmed/19339545 >.

HYNES, R. O. The extracellular matrix: not just pretty fibrils. Science, v. 326, n. 5957, p. 1216-9, Nov 2009. ISSN 1095-9203. Available at: < https://www.ncbi.nlm.nih.gov/pubmed/19965464 >.

INCA. Estimativa 2018: incidência de câncer no Brasil. 2017. Avaialble at: < http://www1.inca.gov.br/estimativa/2018/estimativa-2018.pdf >. Accessed on: 14/04/2019.

IRUELA-ARISPE, M. L.; CARPIZO, D.; LUQUE, A. ADAMTS1: a matrix metalloprotease with angioinhibitory properties. Ann N Y Acad Sci, v. 995, p. 183-90, May 2003. ISSN 0077-8923. Available at: < http://www.ncbi.nlm.nih.gov/pubmed/12814950 >

JANUCHOWSKI, R. et al. Extracellular matrix proteins expression profiling in chemoresistant variants of the A2780 ovarian cancer cell line. Biomed Res Int, v. 2014, p. 365867,2014 . ISSN 2314-6141. Available at: < http://www.ncbi.nlm.nih.gov/pubmed/24804215 >.

JAYSON, G. C. et al. Ovarian Cancer: Lancet. 384: 1376-1388 p. 2014.

JEMAL, A. et al. Global cancer statistics. CA Cancer J Clin, v. 61, n. 2, p. 6990, 2011 Mar-Apr 2011. ISSN 1542-4863. Available at: < http://www.ncbi.nlm.nih.gov/pubmed/21296855 >.

JEON, S.-Y.; CHOI, K.-C. Progesterone is a potent substance which inhibits the migration of ovarian cancer cells by reducing epithelial-mesenchymal transition via progesterone receptor-dependen pathway 2015. 
JEPPSSON, S.; RANNEVIK, G.; THORELL, J. I. Pituitary gonadotrophin secretion during the first weeks of pregnancy. Acta Endocrinol (Copenh), v. 85, n. 1, p. 177-88, May 1977. ISSN 0001-5598. Available at: < http://www.ncbi.nlm.nih.gov/pubmed/324219 >.

JUNQUEIRA, L. C.; CARNEIRO, J. Histologia Básica 12 ed. GUANABARA KOOGAN, 2017.

KALLURI, R. Basement membranes: structure, assembly and role in tumour angiogenesis. Nat Rev Cancer, v. 3, n. 6, p. 422-33, Jun 2003. ISSN 1474-175X. Available at: < http://www.ncbi.nlm.nih.gov/pubmed/12778132 >.

KALLURI, R.; ZEISBERG, M. Fibroblasts in cancer. Nat Rev Cancer, v. 6, n. 5, p. 392-401, May 2006. ISSN 1474-175X. Available at: < http://www.ncbi.nlm.nih.gov/pubmed/16572188 >.

KARIAGINA, A. et al. Progesterone stimulates proliferation and promotes cytoplasmic localization of the cell cycle inhibitor p27 in steroid receptor positive breast cancers. Horm Cancer, v. 4, n. 6, p. 381-90, Dec 2013. ISSN 1868-8500. Available at: $<$ https://www.ncbi.nlm.nih.gov/pubmed/23996077 >.

KAUPPILA, S. et al. Aberrant type I and type III collagen gene expression in human breast cancer in vivo. J Pathol, v. 186, n. 3, p. 262-8, Nov 1998. ISSN 0022-3417. Available at: < http://www.ncbi.nlm.nih.gov/pubmed/10211114 >.

KELLER, E. T.; LI, L. Y. The first Tianjin, China forum on tumor microenvironment. Cancer Res, v. 71, n. 2, p. 310-3, Jan 2011. ISSN 1538-7445. Available at: < https://www.ncbi.nlm.nih.gov/pubmed/21224351 >.

KENNY, $\mathrm{H}$. A. et al. The initial steps of ovarian cancer cell metastasis are mediated by MMP-2 cleavage of vitronectin and fibronectin. J Clin Invest, v. 118, n. 4, p. 1367-79, Apr 2008. ISSN 0021-9738. Available at: < http://www.ncbi.nlm.nih.gov/pubmed/18340378 >.

KESSENBROCK, K.; PLAKS, V.; WERB, Z. Matrix metalloproteinases: regulators of the tumor microenvironment. Cell, v. 141, n. 1, p. 52-67, Apr 2010. ISSN 1097-4172. Available at: < http://www.ncbi.nlm.nih.gov/pubmed/20371345 $>$.

$\mathrm{KIM}, \mathrm{H}$. J. et al. C-MET as a Potential Therapeutic Target in Ovarian Clear Cell Carcinoma. Sci Rep, v. 6, p. 38502, Dec 2016. ISSN 2045-2322. Available at: < https://www.ncbi.nlm.nih.gov/pubmed/27917934 >.

$\mathrm{KISO}, \mathrm{M}$. et al. Long isoform of VEGF stimulates cell migration of breast cancer by filopodia formation via NRP1/ARHGAP17/Cdc42 regulatory network. Int J Cancer, v. 143, n. 11, p. 2905-2918, 12 2018. ISSN 1097-0215. Available at: < https://www.ncbi.nlm.nih.gov/pubmed/29971782 >.

KUNO, K. et al. The carboxyl-terminal half region of ADAMTS-1 suppresses both tumorigenicity and experimental tumor metastatic potential. Biochem Biophys 
Res Commun, v. 319, n. 4, p. 1327-33, Jul 2004. ISSN 0006-291X. Available at: $<$ http://www.ncbi.nlm.nih.gov/pubmed/15194513 $>$.

. Molecular cloning of a gene encoding a new type of metalloproteinasedisintegrin family protein with thrombospondin motifs as an inflammation associated gene. J Biol Chem, v. 272, n. 1, p. 556-62, Jan 1997. ISSN 00219258. Available at: < http://www.ncbi.nlm.nih.gov/pubmed/8995297 > .

KWOK, A. L. et al. Caution over use of ES2 as a model of ovarian clear cell carcinoma. J Clin Pathol, v. 67, n. 10, p. 921-2, Oct 2014. ISSN 1472-4146. Available at: < http://www.ncbi.nlm.nih.gov/pubmed/25049276 > .

LAMBERT, J. et al. ADAMTS-1 and Syndecan-4 intersect in the regulation of cell migration and angiogenesis. The preprint server for biology, 2018.

LAMBERT , J. et al. ADAMTS - 1 and Syndecan - 4 intersect in the regulation of cell migration and angiogenesis. bioRxiv, 2019.

LAWSON, C. D.; RIDLEY, A. J. Rho GTPase signaling complexes in cell migration and invasion. J Cell Biol, v. 217, n. 2, p. 447-457, 02 2018. ISSN 15408140. Available at: < https://www.ncbi.nlm.nih.gov/pubmed/29233866 >.

LE GOFF, C.; CORMIER-DAIRE, V. The ADAMTS(L) family and human genetic disorders. Hum Mol Genet, v. 20, n. R2, p. R163-7, Oct 2011. ISSN 1460-2083. Available at: < http://www.ncbi.nlm.nih.gov/pubmed/21880666 $>$.

LEE, M. et al. ADAMTS13 promotes angiogenesis and modulates VEGFinduced angiogenesis. Microvasc Res, v. 84, n. 2, p. 109-15, Sep 2012. ISSN 1095-9319. Available at: < https://www.ncbi.nlm.nih.gov/pubmed/22626948 >.

LEE, N. V. et al. ADAMTS1 mediates the release of antiangiogenic polypeptides from TSP1 and 2. EMBO J, v. 25, n. 22, p. 5270-83, Nov 2006. ISSN 0261-4189. Available at: < http://www.ncbi.nlm.nih.gov/pubmed/17082774 > .

LEE, P. et al. Expression of progesterone receptor is a favorable prognostic marker in ovarian cancer. Gynecol Oncol, v. 96, n. 3, p. 671-7, Mar 2005. ISSN 0090-8258. Available at: < http://www.ncbi.nlm.nih.gov/pubmed/15721410 >

LEE, T. S. et al. Progesterone Inhibits Endothelial Cell Migration Through Suppression of the Rho Activity Mediated by cSrc Activation. J Cell Biochem, Mar 2015. ISSN 1097-4644. Available at: < http://www.ncbi.nlm.nih.gov/pubmed/25754581 >.

LEE, W.-S. et al. Progesterone inhibits arterial smooth muscle cell proliferation. Nature Medicine, v. 3, n. 9, p. 1005-1008, 1997/09/01 1997. ISSN 1546-170X. Available at: $<$ https://doi.org/10.1038/nm0997-1005 $>$.

LENHARD, M. et al. Steroid hormone receptor expression in ovarian cancer: progesterone receptor $\mathrm{B}$ as prognostic marker for patient survival. BMC Cancer, 
v. 12, p. 553, 2012. ISSN 1471-2407. Available at: < http://www.ncbi.nlm.nih.gov/pubmed/23176303 >.

LI, J. et al. Natural Selection Has Differentiated the Progesterone Receptor among Human Populations. Am J Hum Genet, v. 103, n. 1, p. 45-57, 072018. ISSN 1537-6605. Available at: < https://www.ncbi.nlm.nih.gov/pubmed/29937092 >.

LI, R.; GUNDERSEN, G. G. Beyond polymer polarity: how the cytoskeleton builds a polarized cell. Nat Rev Mol Cell Biol, v. 9, n. 11, p. 860-73, Nov 2008. ISSN 1471-0080. Available at: < https://www.ncbi.nlm.nih.gov/pubmed/18946475 >.

LILI, L. N. et al. Molecular profiling predicts the existence of two functionally distinct classes of ovarian cancer stroma. Biomed Res Int, v. 2013, p. 846387, 2013. ISSN 2314-6141. Available at: < http://www.ncbi.nlm.nih.gov/pubmed/23762861 >.

LIMA, M. A.; DA SILVA, S. V.; FREITAS, V. M. Progesterone acts via the progesterone receptor to induce adamts proteases in ovarian cancer cells. $\mathbf{J}$ Ovarian Res, v. 9, n. 1, p. 9, 2016. ISSN 1757-2215. Available at: < http://www.ncbi.nlm.nih.gov/pubmed/26916548 >.

LIMA, M. A. et al. Levels of ADAMTS proteases and their substrates in epithelialovarian tumors with different behavior. Pathobiology, 2016.

LITWACK G; TJ, S. Manual de Bioquímica com correlações clínicas. São Paulo: Edgard Bliicher, 1998.

LIU, Y.; LIN, L.; ZARNEGAR, R. Modulation of hepatocyte growth factor gene expression by estrogen in mouse ovary. Mol Cell Endocrinol, v. 104, n. 2, p. 173-81, Sep 1994. ISSN 0303-7207. Available at: < https://www.ncbi.nlm.nih.gov/pubmed/7988745 >.

LIU, Y. J.; XU, Y.; YU, Q. Full-length ADAMTS-1 and the ADAMTS-1 fragments display pro- and antimetastatic activity, respectively. Oncogene, v. 25, n. 17, p. 2452-67, Apr 2006. ISSN 0950-9232. Available at: < http://www.ncbi.nlm.nih.gov/pubmed/16314835 >.

LU, P. et al. Extracellular matrix degradation and remodeling in development and disease. Cold Spring Harb Perspect Biol, v. 3, n. 12, Dec 2011. ISSN 19430264. Available at: < https://www.ncbi.nlm.nih.gov/pubmed/21917992 >.

LU, P.; WEAVER, V. M.; WERB, Z. The extracellular matrix: a dynamic niche in cancer progression. J Cell Biol, v. 196, n. 4, p. 395-406, Feb 2012. ISSN 15408140. Available at: < http://www.ncbi.nlm.nih.gov/pubmed/22351925 >.

LUQUE, A.; CARPIZO, D. R.; IRUELA-ARISPE, M. L. ADAMTS1/METH1 inhibits endothelial cell proliferation by direct binding and sequestration of VEGF165. $J$ Biol Chem, v. 278, n. 26, p. 23656-65, Jun 2003. ISSN 0021-9258. Available at: < https://www.ncbi.nlm.nih.gov/pubmed/12716911 >. 
MACHACEK, $M$. et al. Coordination of Rho GTPase activities during cell protrusion. Nature, v. 461, n. 7260, p. 99-103, Sep 2009. ISSN 1476-4687. Available at: < https://www.ncbi.nlm.nih.gov/pubmed/19693013 >.

MAGALHÃES, A.; DIAS, S. Vessels Recruitment by Tumor Cells. Molecular and Cell Biology of Cancer. 2019. (978-3-030-11812-9)

MAKOTO SAEGUSA, M. D.; ISAO OKAYASU, M. D. Progesterone Therapy for Endometrial Carcinoma Reduces Cell Proliferation but Does Not Alter Apoptosis. American Cancer Society. 83: 111-120 p. 1997.

MASUI, T. et al. Expression of METH-1 and METH-2 in pancreatic cancer. Clin Cancer Res, v. 7, n. 11, p. 3437-43, Nov 2001. ISSN 1078-0432. Available at: < http://www.ncbi.nlm.nih.gov/pubmed/11705860 >.

MAYOR, R.; THEVENEAU, E. The neural crest. Development, v. 140, n. 11, p. 2247-51, Jun 2013. ISSN 1477-9129. Available at: < https://www.ncbi.nlm.nih.gov/pubmed/23674598 >.

MBEUNKUI, F.; JOHANN, D. J. Cancer and the tumor microenvironment: a review of an essential relationship. Cancer Chemother Pharmacol, v. 63, n. 4, p. 571-82, Mar 2009. ISSN 1432-0843. Available at: < https://www.ncbi.nlm.nih.gov/pubmed/19083000 >

MEAD, T. J.; APTE, S. S. ADAMTS proteins in human disorders. Matrix Biology, p. 71-72:225-239, 2018.

MISKOLCI, V.; HODGSON, L.; COX, D. Using Fluorescence Resonance Energy Transfer-Based Biosensors to Probe Rho GTPase Activation During Phagocytosis. Methods Mol Biol, v. 1519, p. 125-143, 2017. ISSN 1940-6029. Available at: < https://www.ncbi.nlm.nih.gov/pubmed/27815877 >.

MOSMANN, T. Rapid colorimetric assay for cellular growth and survival: application to proliferation and cytotoxicity assays. J Immunol Methods, v. 65, n. 1-2, p. 55-63, Dec 1983. ISSN 0022-1759. Available at: < http://www.ncbi.nlm.nih.gov/pubmed/6606682 >.

MOSSELMAN, S.; POLMAN, J.; DIJKEMA, R. ER beta: identification and characterization of a novel human estrogen receptor. FEBS Lett, v. 392, n. 1, p. 49-53, Aug 1996. ISSN 0014-5793. Available at: < http://www.ncbi.nlm.nih.gov/pubmed/8769313 >.

MOSYAK, L. et al. Crystal structures of the two major aggrecan degrading enzymes, ADAMTS4 and ADAMTS5. Protein Sci, v. 17, n. 1, p. 16-21, Jan 2008. ISSN 0961-8368. Available at: < https://www.ncbi.nlm.nih.gov/pubmed/18042673 > 
MUELLER, M. M.; FUSENIG, N. E. Friends or foes - bipolar effects of the tumour stroma in cancer. Nat Rev Cancer, v. 4, n. 11, p. 839-49, Nov 2004. ISSN 1474175X. Available at: < http://www.ncbi.nlm.nih.gov/pubmed/15516957 >.

NAGAI, T. et al. Expanded dynamic range of fluorescent indicators for $\mathrm{Ca}(2+)$ by circularly permuted yellow fluorescent proteins. Proc Natl Acad Sci U S A, v. 101, n. 29, p. 10554-9, Jul 2004. ISSN 0027-8424. Available at: < https://www.ncbi.nlm.nih.gov/pubmed/15247428 >.

NAGASE, H.; WOESSNER, J. F. Matrix metalloproteinases. J Biol Chem, v. 274, n. 31, p. 21491-4, Jul 1999. ISSN 0021-9258. Available at: < http://www.ncbi.nlm.nih.gov/pubmed/10419448 >.

NASSER, N. J. Heparanase involvement in physiology and disease. Cell Mol Life Sci, v. 65, n. 11, p. 1706-15, Jun 2008. ISSN 1420-682X. Available at: < http://www.ncbi.nlm.nih.gov/pubmed/18425416 >.

NATARAJAN, S. et al. Collagen Remodeling in the Hypoxic Tumor-Mesothelial Niche Promotes Ovarian Cancer Metastasis. Cancer Res, v. 79, n. 9, p. 22712284, May 2019. ISSN 1538-7445. Available at: < https://www.ncbi.nlm.nih.gov/pubmed/30862717 >.

NIEWIAROWSKI, S. et al. Disintegrins and other naturally occurring antagonists of platelet fibrinogen receptors. Semin Hematol, v. 31, n. 4, p. 289-300, Oct 1994. ISSN 0037-1963. Available at: < http://www.ncbi.nlm.nih.gov/pubmed/7831574 >.

NORIEGA-GUERRA, $H$. et al. ADAMTS-1 disrupts HGF/C-MET signaling and HGF-stimulated cellular processes in fibrosarcoma. Exp Cell Res, v. 363, n. 2, p. 271-282, Feb 2018. ISSN 1090-2422. Available at: < https://www.ncbi.nlm.nih.gov/pubmed/29355494 >.

NORTON, W. H. et al. HSPG synthesis by zebrafish Ext2 and Ext|3 is required for Fgf10 signalling during limb development. Development, v. 132, n. 22, p. 4963-73, Nov 2005. ISSN 0950-1991. Available at: < https://www.ncbi.nlm.nih.gov/pubmed/16221725 >.

OBIKA, M. et al. Tumor growth inhibitory effect of ADAMTS1 is accompanied by the inhibition of tumor angiogenesis. Cancer Sci, v. 103, n. 10, p. 1889-97, Oct 2012. ISSN 1349-7006. Available at: < http://www.ncbi.nlm.nih.gov/pubmed/22776012 >.

PALUCH, E. K.; RAZ, E. The role and regulation of blebs in cell migration. Curr Opin Cell Biol, v. 25, n. 5, p. 582-90, Oct 2013. ISSN 1879-0410. Available at: < https://www.ncbi.nlm.nih.gov/pubmed/23786923 >.

PARRINI, M. C. et al. Pak1 kinase homodimers are autoinhibited in trans and dissociated upon activation by Cdc42 and Rac1. Mol Cell, v. 9, n. 1, p. 73-83, Jan 2002. ISSN 1097-2765. Available at: < https://www.ncbi.nlm.nih.gov/pubmed/11804587 >. 
PARROTT, J. A.; SKINNER, M. K. Developmental and hormonal regulation of hepatocyte growth factor expression and action in the bovine ovarian follicle. Biol Reprod, v. 59, n. 3, p. 553-60, Sep 1998. ISSN 0006-3363. Available at: < https://www.ncbi.nlm.nih.gov/pubmed/9716553 >.

PEARCE, C. L. et al. Increased ovarian cancer risk associated with menopausal estrogen therapy is reduced by adding a progestin. Cancer, v. 115, n. 3, p. 5319, Feb 2009. ISSN 0008-543X. Available at: < http://www.ncbi.nlm.nih.gov/pubmed/19127543 >.

PERTZ, O. et al. Spatiotemporal dynamics of RhoA activity in migrating cells. Nature, v. 440, n. 7087, p. 1069-72, Apr 2006. ISSN 1476-4687. Available at: < https://www.ncbi.nlm.nih.gov/pubmed/16547516 >.

PETERS, H.; MCNATTY, K. P. The Ovary. Barkeley e Los Angeles - California: University of California, 1980.

PICTON, H. M. et al. The in vitro growth and maturation of follicles. Reproduction, v. 136, n. 6, p. 703-15, Dec 2008. ISSN 1741-7899. Available at: $<$ http://www.ncbi.nlm.nih.gov/pubmed/19074213 >.

PORTER, S. et al. The ADAMTS metalloproteinases. Biochem J, v. 386, n. Pt 1, p. 15-27, Feb 2005. ISSN 1470-8728. Available at: < http://www.ncbi.nlm.nih.gov/pubmed/15554875 >.

PRUYNE, D.; BRETSCHER, A. Polarization of cell growth in yeast. J Cell Sci, v. 113 ( Pt 4), p. 571-85, Feb 2000. ISSN 0021-9533. Available at: < https://www.ncbi.nlm.nih.gov/pubmed/10652251 >.

RA, H. J.; PARKS, W. C. Control of matrix metalloproteinase catalytic activity. Matrix Biol, v. 26, n. 8, p. 587-96, Oct 2007. ISSN 0945-053X. Available at: < http://www.ncbi.nlm.nih.gov/pubmed/17669641 >.

RAFFETTO, J. D.; KHALIL, R. A. Matrix metalloproteinases and their inhibitors in vascular remodeling and vascular disease. Biochem Pharmacol, v. 75, n. 2, p. 346-59, Jan 2008. ISSN 0006-2952. Available at: < http://www.ncbi.nlm.nih.gov/pubmed/17678629 >.

RAMACHANDRAN, B. E. A. Novel insights on imaging sex-hormone dependent 1 tumourigenesis in vivo. . Endocr Relat Cancer, p. p.1-32, 2011.

RAO, N. et al. ADAMTS4 and its proteolytic fragments differentially affect melanoma growth and angiogenesis in mice. Int $\mathbf{J}$ Cancer, v. 133, n. 2, p. 294306, Jul 2013. ISSN 1097-0215. Available at: < http://www.ncbi.nlm.nih.gov/pubmed/23319426 >.

RAYNAUD, C. M. et al. DNA damage repair and telomere length in normal breast, preneoplastic lesions, and invasive cancer. Am J Clin Oncol, v. 33, n. 4, 
p. 341-5, Aug 2010. ISSN 1537-453X. Available at: < http://www.ncbi.nlm.nih.gov/pubmed/19884805 >.

REHN, A. P. et al. ADAMTS-1 increases the three-dimensional growth of osteoblasts through type I collagen processing. Bone, v. 41, n. 2, p. 231-8, Aug ISSN 8756-3282. Available at: http://www.ncbi.nlm.nih.gov/pubmed/17560840 $>$.

RENGANATHAN, B. et al. Recombinant TSR1 of ADAMTS5 Suppresses Melanoma Growth in Mice via an Anti-angiogenic Mechanism. Cancers (Basel), v. 10, n. 6, Jun 2018. ISSN 2072-6694. Available at: < https://www.ncbi.nlm.nih.gov/pubmed/29891754 >.

RICCI, M. D. et al. Ginecologia oncótica: aspectos atuais do diagnóstico e tratamento. Barueri - SP: Manole, 2008.

RICCIARDELLI, C. et al. The ADAMTS1 protease gene is required for mammary tumor growth and metastasis. Am J Pathol, v. 179, n. 6, p. 3075-85, Dec 2011. ISSN 1525-2191. Available at: < http://www.ncbi.nlm.nih.gov/pubmed/22001177 $>$.

RICCIARDELLI, C.; RODGERS, R. J. Extracellular matrix of ovarian tumors. Semin Reprod Med, v. 24, n. 4, p. 270-82, Sep 2006. ISSN 1526-8004. Available at: < http://www.ncbi.nlm.nih.gov/pubmed/16944424 >.

RICHARDS, J. S. et al. Regulated expression of ADAMTS family members in follicles and cumulus oocyte complexes: evidence for specific and redundant patterns during ovulation. Biol Reprod, v. 72, n. 5, p. 1241-55, May 2005. ISSN 0006-3363. Available at: < http://www.ncbi.nlm.nih.gov/pubmed/15659705 >.

RIMAN, T. et al. Risk factors for invasive epithelial ovarian cancer: results from a Swedish case-control study. Am J Epidemiol, v. 156, n. 4, p. 363-73, Aug 2002. ISSN 0002-9262. Available at: < http://www.ncbi.nlm.nih.gov/pubmed/12181107 >.

RIMAN, T.; NILSSON, S.; PERSSON, I. R. Review of epidemiological evidence for reproductive and hormonal factors in relation to the risk of epithelial ovarian malignancies. Acta Obstet Gynecol Scand, v. 83, n. 9, p. 783-95, Sep 2004. ISSN 0001-6349. Available at: < http://www.ncbi.nlm.nih.gov/pubmed/15315588 $>$.

RISTOW, C. M.; YAMAMOTO, C. T.; FAVARO, M. Fatores de risco e patogênese das neoplasias malignas epiteliais de ovário: revisão de literatura. Rev Bras Cancerol, v. 52, p. 185-95. , 2006.

RIZZO, M. A. et al. An improved cyan fluorescent protein variant useful for FRET. Nat Biotechnol, v. 22, n. 4, p. 445-9, Apr 2004. ISSN 1087-0156. Available at: < https://www.ncbi.nlm.nih.gov/pubmed/14990965 >. 
ROBKER, R. L. et al. Progesterone-regulated genes in the ovulation process: ADAMTS-1 and cathepsin L proteases. Proc Natl Acad Sci U S A, v. 97, n. 9, p. 4689-94, Apr 2000. ISSN 0027-8424. Available at: < http://www.ncbi.nlm.nih.gov/pubmed/10781075 >.

ROCERETO, T. F. et al. A phase Il evaluation of mifepristone in the treatment of recurrent or persistent epithelial ovarian, fallopian or primary peritoneal cancer: a gynecologic oncology group study. Gynecol Oncol, v. 116, n. 3, p. 332-4, Mar 2010. ISSN 1095-6859. Available at: < https://www.ncbi.nlm.nih.gov/pubmed/19922989 >.

Phase II study of mifepristone (RU486) in refractory ovarian cancer. Gynecol Oncol, v. 77, n. 3, p. 429-32, Jun 2000. ISSN 0090-8258. Available at: $<$ https://www.ncbi.nlm.nih.gov/pubmed/10831354 >.

ROCKS, $\mathrm{N}$. et al. Emerging roles of ADAM and ADAMTS metalloproteinases in cancer. Biochimie, v. 90, n. 2, p. 369-79, Feb 2008. ISSN 0300-9084. Available at: $<$ http://www.ncbi.nlm.nih.gov/pubmed/17920749 $>$.

ADAMTS-1 metalloproteinase promotes tumor development through the induction of a stromal reaction in vivo. Cancer Res, v. 68, n. 22, p. 9541-50, Nov 2008. ISSN 1538-7445. Available at: < http://www.ncbi.nlm.nih.gov/pubmed/19010931 >.

RODGERS, R. J.; IRVING-RODGERS, H. F.; VAN WEZEL, I. L. Extracellular matrix in ovarian follicles. Mol Cell Endocrinol, v. 163, n. 1-2, p. 73-9, May 2000. ISSN 0303-7207. Available at: < http://www.ncbi.nlm.nih.gov/pubmed/10963877 $>$.

RODRÍGUEZ-MANZANEQUE, J. C. et al. Cleavage of syndecan-4 by ADAMTS1 provokes defects in adhesion. Int J Biochem Cell Biol, v. 41, n. 4, p. 800-10, Apr 2009. ISSN 1878-5875. Available at: < http://www.ncbi.nlm.nih.gov/pubmed/18775505 >.

ADAMTS1 cleaves aggrecan at multiple sites and is differentially inhibited by metalloproteinase inhibitors. Biochem Biophys Res Commun, v. 293, n. 1, p. 501-8, Apr 2002. ISSN 0006-291X. Available at: < http://www.ncbi.nlm.nih.gov/pubmed/12054629 >.

ROMANO, A. et al. Two functionally relevant polymorphisms in the human progesterone receptor gene $(+331 \mathrm{G} / \mathrm{A}$ and progins) and the predisposition for breast and/or ovarian cancer. Gynecol Oncol, v. 101, n. 2, p. 287-95, May 2006. ISSN 0090-8258. Available at: < http://www.ncbi.nlm.nih.gov/pubmed/16360811 $>$.

ROWE, R. G.; WEISS, S. J. Breaching the basement membrane: who, when and how? Trends Cell Biol, v. 18, n. 11, p. 560-74, Nov 2008. ISSN 1879-3088. Available at: < https://www.ncbi.nlm.nih.gov/pubmed/18848450 > 
ROY, R. et al. Metalloproteinases and their roles in human cancer. Anat Rec (Hoboken), Jun 2019. ISSN 1932-8494. Available at: < https://www.ncbi.nlm.nih.gov/pubmed/31168956 >.

ROZANOV, D. V. et al. Aberrant, persistent inclusion into lipid rafts limits the tumorigenic function of membrane type-1 matrix metalloproteinase in malignant cells. Exp Cell Res, v. 293, n. 1, p. 81-95, Feb 2004. ISSN 0014-4827. Available at: $<$ http://www.ncbi.nlm.nih.gov/pubmed/14729059 >

RUSSELL, D. L. et al. Processing and localization of ADAMTS- 1 and proteolytic cleavage of versican during cumulus matrix expansion and ovulation. J Biol Chem, v. 278, n. 43, p. 42330-9, Oct 2003. ISSN 0021-9258. Available at: < http://www.ncbi.nlm.nih.gov/pubmed/12907688 >.

SALANI, R. et al. Expression of extracellular matrix proteins in ovarian serous tumors. Int J Gynecol Pathol, v. 26, n. 2, p. 141-6, Apr 2007. ISSN 0277-1691. Available at: < http://www.ncbi.nlm.nih.gov/pubmed/17413980 >

SANTIBANEZ, J. F. et al. Transforming growth factor- $\beta$, matrix metalloproteinases, and urokinase-type plasminogen activator interaction in the cancer epithelial to mesenchymal transition. Dev Dyn, v. 247, n. 3, p. 382-395, Mar 2018. ISSN 1097-0177. Available at: < https://www.ncbi.nlm.nih.gov/pubmed/28722327 >.

SAPOZNIK, S. et al. Gonadotropin-regulated lymphangiogenesis in ovarian cancer is mediated by LEDGF-induced expression of VEGF-C. Cancer Res, v. 69 , n. 24, p. 9306-14, Dec 2009. ISSN 1538-7445. Available at: < http://www.ncbi.nlm.nih.gov/pubmed/19934313 >.

SCHAMS, D.; BERISHA, B. Steroids as local regulators of ovarian activity in domestic animals. Domest Anim Endocrinol, v. 23, n. 1-2, p. 53-65, Jul 2002. ISSN 0739-7240. Available at: < http://www.ncbi.nlm.nih.gov/pubmed/12142226 $>$.

SCHILDKRAUT, J. M. et al. Impact of progestin and estrogen potency in oral contraceptives on ovarian cancer risk. J Natl Cancer Inst, v. 94, n. 1, p. 32-8, Jan 2002. ISSN 0027-8874. Available at: < http://www.ncbi.nlm.nih.gov/pubmed/11773280 >.

$\mathrm{SCHOCK}, \mathrm{H}$. et al. Early pregnancy sex steroids and maternal risk of epithelial ovarian cancer. Endocr Relat Cancer, v. 21, n. 6, p. 831-44, 2014. ISSN 14796821. Available at: < http://www.ncbi.nlm.nih.gov/pubmed/25270324 >.

SHIMONOVITZ, S. et al. Expression of gelatinase B by trophoblast cells: downregulation by progesterone. Am J Obstet Gynecol, v. 178, n. 3, p. 457-61, Mar 1998. ISSN 0002-9378. Available at: < https://www.ncbi.nlm.nih.gov/pubmed/9539508 >.

SHINDO, T. et al. ADAMTS-1: a metalloproteinase-disintegrin essential for normal growth, fertility, and organ morphology and function. J Clin Invest, v. 105, 
n. 10, p. 1345-52, May 2000. ISSN 0021-9738. Available at: < http://www.ncbi.nlm.nih.gov/pubmed/10811842 >.

SHOZU, M. et al. ADAMTS-1 is involved in normal follicular development, ovulatory process and organization of the medullary vascular network in the ovary. J Mol Endocrinol, v. 35, n. 2, p. 343-55, Oct 2005. ISSN 0952-5041. Available at: < http://www.ncbi.nlm.nih.gov/pubmed/16216914 >.

SILVA, T. A. et al. AHNAK enables mammary carcinoma cells to produce extracellular vesicles that increase neighboring fibroblast cell motility. Oncotarget, v. 7, n. 31, p. 49998-50016, Aug 2016. ISSN 1949-2553. Available at: < https://www.ncbi.nlm.nih.gov/pubmed/27374178 >.

SPANO, D. et al. Molecular networks that regulate cancer metastasis. Semin Cancer Biol, v. 22, n. 3, p. 234-49, Jun 2012. ISSN 1096-3650. Available at: < https://www.ncbi.nlm.nih.gov/pubmed/22484561 >.

SPIERING, D.; HODGSON, L. Multiplex imaging of Rho family GTPase activities in living cells. Methods Mol Biol, v. 827, p. 215-34, 2012. ISSN 1940-6029. Available at: < https://www.ncbi.nlm.nih.gov/pubmed/22144278 >.

STANTON, $\mathrm{H}$. et al. Proteoglycan degradation by the ADAMTS family of proteinases. Biochim Biophys Acta, v. 1812, n. 12, p. 1616-29, Dec 2011. ISSN 0006-3002. Available at: < http://www.ncbi.nlm.nih.gov/pubmed/21914474 >.

STAUN-RAM, E.; SHALEV, E. Human trophoblast function during the implantation process. Reprod Biol Endocrinol, v. 3, p. 56, Oct 2005. ISSN 14777827. Available at: < https://www.ncbi.nlm.nih.gov/pubmed/16236179 >.

SUN, Y. Translational horizons in the tumor microenvironment: harnessing breakthroughs and targeting cures. Med Res Rev, v. 35, n. 2, p. 408-36, Mar 2015. ISSN 1098-1128. Available at: < https://www.ncbi.nlm.nih.gov/pubmed/25588753 >.

SWARTZ, M. A. et al. Tumor microenvironment complexity: emerging roles in cancer therapy. Cancer Res, v. 72, n. 10, p. 2473-80, May 2012. ISSN 15387445. Available at: < https://www.ncbi.nlm.nih.gov/pubmed/22414581 >.

SYED, V. et al. Expression of gonadotropin receptor and growth responses to key reproductive hormones in normal and malignant human ovarian surface epithelial cells. Cancer Res, v. 61, n. 18, p. 6768-76, Sep 2001. ISSN 0008-5472. Available at: < http://www.ncbi.nlm.nih.gov/pubmed/11559549 >.

TALLANT, C. et al. On the relevance of the Met-turn methionine in metzincins. $\mathbf{J}$ Biol Chem, v. 285, n. 18, p. 13951-7, Apr 2010. ISSN 1083-351X. Available at: < https://www.ncbi.nlm.nih.gov/pubmed/20202937 >.

TAN, I. A. et al. ADAMTS1 Promotes Adhesion to Extracellular Matrix Proteins and Predicts Prognosis in Early Stage Breast Cancer Patients. Cell Physiol 
Biochem, v. 52, n. 6, p. 1553-1568, 2019. ISSN 1421-9778. Available at: < https://www.ncbi.nlm.nih.gov/pubmed/31135123 >.

TAN, I. E. A.; RICCIARDELLI, C.; RUSSELL, D. L. The metalloproteinase ADAMTS1: a comprehensive review of its role in tumorigenic and metastatic pathways. Int J Cancer. 133: 2263-76 p. 2013.

TANIGUCHI, F. et al. Hepatocyte growth factor promotes cell proliferation and inhibits progesterone secretion via PKA and MAPK pathways in a human granulosa cell line. Mol Reprod Dev, v. 68, n. 3, p. 335-44, Jul 2004. ISSN $1040-$ 452X. Available at: < https://www.ncbi.nlm.nih.gov/pubmed/15112327 >.

TIESZEN, C. R. et al. Antiprogestin mifepristone inhibits the growth of cancer cells of reproductive and non-reproductive origin regardless of progesterone receptor expression. BMC Cancer, v. 11, p. 207, May 2011. ISSN 1471-2407. Available at: < https://www.ncbi.nlm.nih.gov/pubmed/21619605 > .

TUNG, K. H. et al. Reproductive factors and epithelial ovarian cancer risk by histologic type: a multiethnic case-control study. Am J Epidemiol, v. 158, n. 7, p. 629-38, Oct 2003. ISSN 0002-9262. Available at: < http://www.ncbi.nlm.nih.gov/pubmed/14507598 >.

TYAN, S. W. et al. Breast cancer cells induce stromal fibroblasts to secrete ADAMTS1 for cancer invasion through an epigenetic change. PLoS One, v. 7, n. 4, p. e35128, 2012. ISSN 1932-6203. Available at: < http://www.ncbi.nlm.nih.gov/pubmed/22514714 >.

UZUMCU, M. et al. Immunolocalization of the hepatocyte growth factor (HGF) system in the rat ovary and the anti-apoptotic effect of HGF in rat ovarian granulosa cells in vitro. Reproduction, v. 132, n. 2, p. 291-9, Aug 2006. ISSN 1470-1626. Available at: < https://www.ncbi.nlm.nih.gov/pubmed/16885537 >.

VAN DER HORST, P. H. et al. Progesterone inhibits epithelial-to-mesenchymal transition in endometrial cancer. PLoS One, v. 7, n. 1, p. e30840, 2012. ISSN 1932-6203. Available at: < http://www.ncbi.nlm.nih.gov/pubmed/22295114 >.

VAN STAVEREN, W. C. et al. Human cancer cell lines: Experimental models for cancer cells in situ? For cancer stem cells? Biochim Biophys Acta, v. 1795, n. 2, p. 92-103, Apr 2009. ISSN 0006-3002. Available at: < http://www.ncbi.nlm.nih.gov/pubmed/19167460 >.

VOIGT, L. F. et al. Progestagen supplementation of exogenous oestrogens and risk of endometrial cancer. Lancet, v. 338, n. 8762, p. 274-7, Aug 1991. ISSN 0140-6736. Available at: < http://www.ncbi.nlm.nih.gov/pubmed/1677110 >.

VÁZQUEZ, F. et al. METH-1, a human ortholog of ADAMTS-1, and METH-2 are members of a new family of proteins with angio-inhibitory activity. J Biol Chem, v. 274 , n. 33 , p. 23349-57, Aug 1999. ISSN 0021-9258. Available at: < http://www.ncbi.nlm.nih.gov/pubmed/10438512 >. 
. Progesterone regulates proliferation of endothelial cells. J Biol Chem, v. 274, n. 4, p. 2185-92, Jan 1999. ISSN 0021-9258. Available at: < https://www.ncbi.nlm.nih.gov/pubmed/9890981 >.

WEEN, M. P.; OEHLER, M. K.; RICCIARDELLI, C. Role of Versican, Hyaluronan and CD44 in Ovarian Cancer Metastasis. Int J Mol Sci, v. 12, n. 2, p. 1009-29, 2011. ISSN 1422-0067. Available at: < http://www.ncbi.nlm.nih.gov/pubmed/21541039 >.

WHEELER, A. P.; RIDLEY, A. J. Why three Rho proteins? RhoA, RhoB, RhoC, and cell motility. Exp Cell Res, v. 301, n. 1, p. 43-9, Nov 2004. ISSN 0014-4827. Available at: < http://www.ncbi.nlm.nih.gov/pubmed/15501444 >.

WOODRUFF, T. K.; SHEA, L. D. The role of the extracellular matrix in ovarian follicle development. Reprod Sci, v. 14, n. 8 Suppl, p. 6-10, Dec 2007. ISSN 1933-7205. Available at: < http://www.ncbi.nlm.nih.gov/pubmed/18089604 >.

WYLLIE, A. H.; KERR, J. F.; CURRIE, A. R. Cell death: the significance of apoptosis. Int Rev Cytol, v. 68, p. 251-306, 1980. ISSN 0074-7696. Available at: < http://www.ncbi.nlm.nih.gov/pubmed/7014501 >.

YANG, C. Y.; CHANALARIS, A.; TROEBERG, L. ADAMTS and ADAM metalloproteinases in osteoarthritis - looking beyond the 'usual suspects'. Osteoarthritis Cartilage, v. 25, n. 7, p. 1000-1009, 07 2017. ISSN 1522-9653. Available at: < https://www.ncbi.nlm.nih.gov/pubmed/28216310 > .

YUEXIN LIU, P. et al. Association of Somatic Mutations of ADAMTS Genes With Chemotherapy Sensitivity and Survival in High-Grade Serous Ovarian Carcinoma. JAMA Oncology 2015.

ZUO, L.; LI, W.; YOU, S. Progesterone reverses the mesenchymal phenotypes of basal phenotype breast cancer cells via a membrane progesterone receptor mediated pathway. Breast Cancer Res, v. 12, n. 3, p. R34, 2010. ISSN 1465542X. Available at: < https://www.ncbi.nlm.nih.gov/pubmed/20540763 > 